\title{
The Possible Effect of Space Weather Factors on Various Physiological Systems of the Human Organism
}

\author{
Tatiana Alexandrovna Zenchenko ${ }^{1,2, *(D)}$ and Tamara Konstantinovna Breus ${ }^{1}$ \\ 1 Space Research Institute, Russian Academy of Sciences, 117997 Moscow, Russia; breus36@mail.ru \\ 2 Institute of Theoretical and Experimental Biophysics, Russian Academy of Sciences, 142290 Pushchino, Russia \\ * Correspondence: zench@mail.ru; Tel.: +7-910-455-7844
}

Citation: Zenchenko, T.A.; Breus, T.K. The Possible Effect of Space Weather Factors on Various Physiological Systems of the Human Organism. Atmosphere 2021, 12, 346. https://doi.org/10.3390/ atmos12030346

Academic Editors: Jonè Venclovienè and Georgios Balasis

Received: 15 December 2020

Accepted: 4 March 2021

Published: 6 March 2021

Publisher's Note: MDPI stays neutral with regard to jurisdictional claims in published maps and institutional affiliations.

Copyright: (C) 2021 by the authors. Licensee MDPI, Basel, Switzerland. This article is an open access article distributed under the terms and conditions of the Creative Commons Attribution (CC BY) license (https:// creativecommons.org/licenses/by/ $4.0 /)$.

\begin{abstract}
A systematic review of heliobiological studies of the last 25 years devoted to the study of the potential influence of space weather factors on human health and well-being was carried out. We proposed three criteria (coordinates), according to which the work on solar-biospheric relations was systematized: the time scale of data sampling (years, days, hours, minutes); the level of organization of the biological system under study (population, group, individual, body system); and the degree of system response (norm, adaptation, failure of adaptation (illness), disaster (death)). This systematic review demonstrates that three parameters mentioned above are closely related in the existing heliobiological studies: the larger the selected time scale, the higher the level of estimated biological system organization and the stronger the potential response degree is. The long-term studies are devoted to the possible influence of solar activity on population disasters, i.e., significant increases in morbidity and mortality. On a daily scale, a probable effect of geomagnetic storms and other space weather events on short-term local outbreaks of morbidity is shown as well as on cases of deterioration in people functional state. On an intraday scale, in the regular functioning mode, the heart and brain rhythms of healthy people turn to be synchronized with geomagnetic field variations in some frequency ranges, which apparently is the necessary organism's existence element. The applicability of different space weather indices at different data sampling rates, the need to take into account the contribution of meteorological factors, and the prospects for an individual approach in heliobiology are discussed. The modern important results of experiments on modeling the action of magnetic storms in laboratory conditions and the substantiation of possible theoreical mechanisms are described. These results provide an experimental and theoretical basis for studies of possible connections of space weather and human health.
\end{abstract}

Keywords: Heliobiology; space weather factors; human health; human magneto sensitivity; cardiovascular system; geomagnetic activity; Schumann resonance

\section{Introduction: Systematizing the Question and Setting the Problem}

Heliobiology studies the possible impact of space weather ( $\mathrm{SpW}$ ) factors, including solar activity (SA), heliospheric and geomagnetic processes, on biological systems at different levels, from individual cells to populations and ecosystems.

The foundation of heliobiology as a science, with the formulation of its goals, tasks, and methods, was laid 100 years ago by the works of A.L. Chizhevsky, who already pointed to the Sun as the possible root cause of 11-year rhythms found in the dynamics of various epidemics [1-3]. Since then, over the years, the goal of heliobiology has been to prove the influence of solar processes on the biosphere and to search for new examples of such influence. Such extensive and long-term proof was necessary because modern physics could not explain the mechanism of action of factors of such low intensity on living systems.

The main stages of key concepts development of the probable biotropic role of SpW factors were summarized in a number of books [4-10], and presented in numerous international conferences materials in 1992-2013 [11-14]. 
In 2006, Palmer et al. [15] published an extensive review with a critical analysis of contemporary results of heliobiological studies. They concluded that a number of heliobiological effects could be considered reliably confirmed; however, the potential physical and medico-biological mechanisms explaining the effect had not been adequately worked out yet.

In 2016, another review was published [16], presenting the results obtained using methodological approaches new to heliobiology, in which the main emphasis is not on finding correlations, but on comparing biological and cosmic rhythms, which made it possible to identify a new class of potential SpW effects. The theoretical development difficulties of the atomic-molecular mechanism explaining the possible sensitivity of biosystems to weak magnetic fields are considered. The authors conclude that "the biological effect of very weak alternating magnetic fields associated with solar and geomagnetic activity is real," but a physically accurate explanation of this effect has not been developed by the time of this writing.

Examples of biotropy (i.e., the potential ability to influence living systems) of SpW factors in the two above-mentioned reviews refer to only one class of phenomena: bursts of increased morbidity and mortality correlated with the moments of geomagnetic storms (GMS). However, the area of possible biological effects of $\mathrm{SpW}$ is much wider. The living beings seem to be able to respond not only to extreme changes in environmental factors, such as GMS, but also to the variations within the normal range. This reaction turns out to be not so catastrophic, but still rather important for the body.

The study of calm, normal modes of living systems reaction to the changes in SpW is necessary for understanding of Sun-biosphere system fundamental internal relationships. Without understanding these mechanisms, it is also impossible to predict the probable moments of breakdown in living systems functioning, which could be manifested as catastrophes of various scales, from planetary epidemics to individual pacemaker failure and one specific cardiac arrest.

Still, there are no reviews summarizing views and results of SpW factors possible influence on healthy people.

There are several large scientific directions staying close or partially intersected to heliobiology, but being different in the object and research methods.

First, these are studies dedicated to the biological effects of ionizing radiation, both anthropogenic and natural. This includes $\mathrm{X}$-rays and gamma rays, neutrons, alpha, beta particles, and others, with energies that allow them to ionize atoms and molecules. Ionizing radiation of solar and galactic origin is almost absorbed by Earth's atmosphere and presents the problem mainly for space flights $[10,17,18]$. The area of intersection of this direction with traditional heliobiology is related to the study of the possible biological effects of solar flares (SF), where high-energy particles reach Earth's surface.

Secondly, this is magnetobiology, which studies the biological effects of magnetic fields (MFs) action with characteristics of the magnetic component $\mathrm{B}=0 \ldots 10 \mathrm{~T}, \mathrm{f}=0 \ldots 10^{9}$ $\mathrm{Hz}$, as well as the sensitivity of organisms to spatial heterogeneities of GMF (homing) [19]. Heliobiology deals only with a small part of the specified range, including natural MFs.

Finally, there are chronobiology (biorhythmology) and chronomedicine, which deal with the issues of the temporal organization of biological objects [5]. This direction intersects with heliobiology in the study of the possible influence of SpW factors on the characteristics of biological rhythms.

A large number of studies are devoted to each of these areas. In our review, we touch upon them to the extent that their results intersect with heliobiology.

Due to the limited scope of the publication, the possible biological effects of atmospheric factors that are influenced by SpW, such as atmospheric electricity, thunderstorms and infrasound, remained outside the scope of consideration. At the same time, we pay attention to situations in which one can suspect a simultaneous and combined effect of space and terrestrial weather factors on living systems. 
The objectives of this work were to systematize the results obtained over the past 25 years on the possible responses of various human physiological systems to SpW factors in different time scales, while paying special attention to precisely reversible, noncatastrophic reactions, since there is every reason to assume that such reactions are variants of the norm-less pronounced than illness or death, but practically comprehensive.

Studies of the potential SpW effects on different body systems vary greatly in scope.

The largest number of studies is devoted to the possible reactions of the cardiovascular and autonomic nervous systems, as well as (to a lesser extent) the brain and endocrine system. These results are included in the review. The responses of other physiological systems of the (such as the immune, digestive, or blood system) have been studied to a lesser extent [20-23], and the results obtained on them cannot yet be systematized due to their scarcity. Therefore, they were left for consideration in future.

Three measurements can be formulated according to which it is advisable to distinguish and systematize the existing results of heliobiological studies:

- The sampling rate of experimental data (years, days, hours, minutes, seconds);

- The level of organization of the studied biological systems (population, group, body, body system, organ, cell, biomolecule);

- $\quad$ The degree of probable biosystem response $(1=$ norm (within the variation of the norm and without a shift in the mean value); 2 = adaptation (reversible shift in the mean values of bioparameters); 3 = failure of adaptation (disease); 4 = death of the organism).

The fourth criterion for systematization is the design of the data collection methodology. There are three main approaches here, each with its own advantages and limitations:

- Population studies, in which datasets on sudden deaths or hospital admissions for exacerbations of various diseases serve as materials for analysis;

- Laboratory and clinical studies, which are based on observations and comparisons of groups of sick and healthy people during GMS or other SpW events;

- Individual monitoring, which involves multiple repeated measurements of a certain physiological indicator in the same person for a long time.

When considering and analyzing the results obtained in each time scale, we paid attention to whether the potential heliobiological effect was detected at a given level, in which form of system response (catastrophic or reversible) it was observed, and whether it was possible to draw conclusions about its specific time-frequency and population characteristics.

\section{Features of the Use of Solar-Geospheric Indicators in Heliobiology}

\subsection{Evolution of the Problem Statement}

A.L. Chizhevsky at one time formulated the main task of heliobiology as proving the existence of the influence of solar rhythms on the biosphere, from bacteria to humans $[1,2]$. In his works, he spoke about the importance of comparing biological time series with solar indices as characterizing the primary source. In addition, according to the scientific concepts of that time, sunspots through special radiation could reach Earth's surface, influencing living beings. These two circumstances-the goal and the ideas about the possible mechanisms-determined the popularity in heliobiology, first of all, of solar indices.

The concept of the physical mechanisms of solar-terrestrial relationships has been dramatically changed during last 100 years. At the same time, the direction of heliobiological research has changed too. Currently the main task is to identify and study specific physical agents that can transmit the SpW influence into the biosphere, as well as the probable mechanisms of their influence on living systems.

The discovery of large-scale structures of solar wind (SW), the sector structure of the interplanetary magnetic field, and the mechanisms of solar energy transfer to the 
magnetosphere allowed heliobiology to rely on these discoveries in terms of describing the mechanisms of possible action of SpW factors.

There are two types of solar and geophysical data being used currently in heliobiological studies: continuous time series of different indices and samples of days corresponding to a specific class of SpW events in near-earth space, such as solar flares of a high class, solar proton events (SPEs), GMSs of different classes, days with abnormally low geomagnetic activity (GMA) called "magnetic silence" and high galactic cosmic ray intensity (GCR), Forbush decreases (FDs), etc.

Methodological aspects of the applicability of these datasets at different time scales have not yet been discussed in the heliobiological literature. In our opinion, the beginning of a broad scientific discussion of these aspects and the development of generally accepted criteria is an actual task, since their absence at present greatly complicates the comparison of the results obtained by different researchers.

\subsection{Annual Scale}

The main task of heliobiological research on an annual scale is to reveal the 11-year rhythm in various biospheric processes. For this, a comparison of the extremes of biological time series with the number of sunspots (or its analog in Wolf numbers (WN), the flux of radio emission $10.7 \mathrm{~cm}$ from the Sun (RF10.7), the intensity of ultraviolet radiation and galactic cosmic rays (GCR) are traditionally used.

All of these physical parameters are highly correlated with each other. The periods of high SA are characterized by higher GMA and higher surface temperature, so these parameters also have an 11-year periodicity [24].

Thus, the close correlation of solar, geophysical, and climatic parameters on an annual scale leads to the assumption that detected synchronicities of biological and solar rhythmicity can tell us nothing about the possible physical nature of SA impact on the biosphere.

\subsection{Daily Scale}

The main task of heliobiology, solved on a daily scale of data, is to identify among the many interrelated SpW events those during which the most pronounced reactions of biological systems are observed. Thus, one of the important points is the ability to reliably distinguish such SpW events on a time scale.

Solar energy is transmitted to Earth through three channels: through electromagnetic radiation, solar cosmic rays (SCR) and through the disturbed structures of the SW plasma.

Electromagnetic radiation (ultraviolet and X-rays) from a solar flare reaches Earth in $8 \mathrm{~min}$ and causes a change in the ionosphere state, which can affect living beings. Traditionally, time series of daily WN and RF values are widely used to describe this class of events in heliobiology.

Since flares are probabilistic in nature, the daily WN values weakly correlate with the daily dynamics of the flare activity. To describe the latter, it is more convenient to use the official SF catalogs or days of X-ray bursts. If for solving the problem requires a continuous time series, the flash index (FI), equal to the product of the point index of the flash intensity by its duration in minutes, can be used [25-27].

In some heliobiological studies, especially retrospective ones, daily WN data to characterize periods of increased GMA are used. However, the geoeffectiveness of SF (i.e., the probability that they will generate the GMS) is only $40-60 \%$, therefore, it is not enough to use only solar observations to predict the development of GMS [28].

Radio emission in the centimeter range increases during SF; however, in the dynamics of the RF10.7 index, this increase is practically not manifested due to the noncomparability of the flare durations (maximum several tens of minutes) and the average index time $(24 \mathrm{~h})$.

Consequently, the daily time series of the number of sunspots, solar flares, and geomagnetic storms are largely independent, and the variations in the daily values of the WN index do not describe any physical process occurring in the habitats of living 
organisms. Thus, although the WN and RF10.7 indices have diurnal resolution, their application in heliobiology on a diurnal scale is ineffective.

If a flare occurs in a suitable region of the Sun, about $10 \mathrm{~min}$ after its maximum, the most energetic protons of the SCRs begin to come to Earth. X-ray bursts and SPEs are interesting for heliobiology in that their effects on the near-Earth space are significantly ahead of the onset of the GMS, and the moments of their onset are distinguishable on the daily scale of data sampling.

The importance of X-ray bursts and SPEs during SFs lies in their influence on the parameters of the main modes of Schumann resonance (SR); the frequency of the first mode increases due to bursts of X-ray radiation and decreases due to SPE [29-31].

Additionally, in the case of very high energy particles in the SPE, they can reach Earth's surface, causing ground level enhancement (GLE). This phenomenon is potentially capable of exerting a significant ionizing effect on living organisms. However, such surface events are too rare for a systematic study of their possible biological effects: a total of 70 GLEs were recorded during SA cycles 17-23, and only two in the current 24th cycle [32].

At present, in heliobiology there is no clear understanding of the entire complex of intermediate links and mechanisms by which perturbations in SW can affect the state of living organisms, and, therefore, what classes of events should be studied. Traditionally, the most widespread study of the possible biological effects of GMS.

Three large-scale SW structures can cause GMS, because they may include the longterm southern Bz component of the interplanetary magnetic field: (1) Corotating Interaction Region (CIR) - a compression region before fast SW stream from the coronal hole, (2) body of Coronal Mass Ejection in the interplanetary space (ICME), and (3) Sheath-a compression region before fast ICME [28,33-35]. Authors of some papers include Sheaths into ICMEs [36]. It has been shown that the biological effects observed with GMS of different origins are very different $[9,37-39]$, therefore it is necessary to take into account their origin for accurate analysis of possible bioeffects due to GMS.

In addition, samples of days with such events in near-Earth space as an increase in SW density and velocity above a certain value, days of large intervals of negative values of the Bz-component of the interplanetary magnetic field, days of arrival of ICMEs and Forbush decreases are used.

A sharp increase in SW pressure changes the configuration of the magnetosphere and can affect the SR parameters [40], the generation of Pc1 geomagnetic pulsations [41], and the microphysics of clouds, temperature, and dynamics in the troposphere and, through them, the global electrical circuit of the atmosphere [42,43]. All of these factors can be agents transmitting influence from the SW to the biosphere.

In heliobiological studies, there are currently no generally accepted criteria for the choice of GMS classes, or GMA indices reflecting different types of geomagnetic disturbances. The only fairly widely used criterion is the 5-level gradation of GMS intensity according to the values of the Ap or Dst index (for example, using the minimum Dst value as an indicator, GMS can be classified as weak $(<-30 \mathrm{nT})$, moderate $(<-50 \mathrm{nT})$, strong $(<-100 \mathrm{nT})$, severe $(<-200 \mathrm{nT})$, and great $(<-350 \mathrm{nT})$ [44].

It is also important to consider that the $\mathrm{AE}$ and Dst indices are measured at different geomagnetic latitudes and are sensitive to different current systems: auroral electrojet (magnetic substorms) and ring current (magnetic storms). The first class makes a large contribution to high-latitude events, while the second to low-latitude ones. The Kp index is sensitive to both storms and substorms and does not allow to distinguish which type of storm caused its increase [28].

The daily data sampling format is the most common in heliobiology, since it has a number of important advantages for the class of problems being solved now. First, it is most commensurate with significant SpW events and the possible biosphere's reactions to them: the time of passage of ICME from the Sun to Earth or the duration of GMS is several days. In daily data, these events are easy to track and their main classes can be 
distinguished on the timeline. Secondly, this scale avoids the unnecessary contribution of both 24-h and annual rhythms present in biological and geophysical data.

\subsection{Intraday Scale}

Of the ranges electromagnetic atmospheric noises [45], two are considered in heliobiology: ultra-low frequency (ULF; $10^{-3}-1 \mathrm{~Hz}$ ) and extremely low frequency (ELF; 3-3000 $\mathrm{Hz}$ ). Oscillations of the former arise as resonances in the magnetospheric cavity due to the interaction of SW particles with the magnetosphere; resonances of the latter are the main modes of the Earth-ionosphere resonator in the range from 5 to $60 \mathrm{~Hz}$.

These two resonators attracted attention several decades ago due to the proximity of their fundamental frequencies to the characteristic frequencies of the human heart rate $(1 \mathrm{~Hz})$ and the alpha rhythm of the brain $(8 \mathrm{~Hz})$. It was a popular assumption that the possible mechanism of the biotropic action of EMF is a direct resonance type.

Two types of geomagnetic pulsations are considered in heliobiological studies: Pc1 (period 0.2-5 s; mean intensity $1 \mathrm{nT}$ ) and Pc5 (period 150-600 s; mean intensity $300 \mathrm{nT}$ ).

The generation of Pc1 pulsations is characteristic of the recovery phase of a GMS $3-5$ days after the sudden onset of the storm, but in rare cases these are observed even several hours before the sudden onset [41].

Pc5 pulsations differ from other types of stable geomagnetic pulsations not only in their large periods and amplitudes, but also in their clear connection with the development of substorms [46]. The excitation of Pc5-6 geomagnetic pulsations with $\mathrm{T}=\sim 5-20 \mathrm{~min}$ is characteristic of the initial phase of the GMS. [47]. Since Pc5-6 are closely related to the development of GMS, a special geophysical index (ultra-low frequency index, ULF) was developed to describe them [48]. The frequencies of these pulsations do not directly coincide with any well-known biological rhythms, such as the human pulse rate. However, this frequency range contains the main frequencies of a number of physiological processes that regulate the tone of large and small vessels [49]. Thus, Pc5-6 can be a very likely candidate for the role of an agent determining the possible biotropic effect of GMS.

Schumann resonance is the most popular potential candidate for a biotropic GMF agent in heliobiology [50]. SR arises from a natural waveguide formed by Earth and the ionosphere, into which the energy of lightning discharges enters [51]. Since thunderstorm activity occurs constantly, oscillations in the fundamental modes of the resonator are constantly present.

SpW events affect the frequency-amplitude parameters of these modes through changes in the parameters of the upper shell of the resonator, i.e., ionosphere. This influence is observed both in the 11-year SA cycle [52] and during individual gamma and X-ray flares [52,53], arrival of SW shock waves [40], or SPEs [29,30].

Thus, the analysis of the applicability of various solar and geophysical parameters in heliobiology shows that each of the time scales—annual, daily, and intraday-requires its own specific set of space weather characteristics, corresponding to the main problem solved in each time scale.

\section{Review of the Results of Heliobiology}

Following the classification according to the three criteria proposed in the Introduction, we consider the available array of heliobiological studies, going down the time sampling scale from the largest to the smallest. We look in more detail at the results related to less pronounced levels of physiological response, that is, without an average shift or with a reversible shift.

\subsection{Annual Scale}

In his book, Chizhevsky gave a long list of examples, obtained by various researchers, of 11-year recurrence in the frequency of storms, hurricanes, tornadoes, and precipitation, the number of polar icebergs, the water levels of lakes, and the width of tree rings [3]. Clearly, the SA rhythm has been found in a great many biospheric processes. 
In the field of human health, only indicators related to the population as a whole can be examined on this time scale. Here, rhythms in the occurrence of epidemics [54-57] and strong surges in mortality [58] and non-infectious diseases, such as cardiovascular [59,60] and mental [22] diseases, has attracted attention.

In a number of studies, the 11-year rhythm is simply associated with the general level of SA $[55,56,60]$, while in others the hypotheses about the action of a certain physical factor are expressed. Davis and Lowell [22] and Hayes [54] believe that the active element determining the 11-year rhythm of morbidity is variations in the level of ultraviolet radiation in the surface, as well as radio emission bursts, especially in the highest (chaotic) SA cycles.

Vieira and colleagues [58] see the decisive role of GCR in influencing the physicochemical properties of Earth's atmosphere, as well as the biosphere. Wickramasinghe [57] believes that the intensity of the COVID-19 pandemic is due, among other things, to the deepest SA minimum in 100 years and an ultra-strong cosmic ray burst in December 2019.

These examples show that the possible effect of SA on terrestrial processes is still manifested in a long-term rhythm, despite the strong anthropogenic contribution to the biosphere. At the level of the human population, this influence, as it did 100 years ago, manifests as bursts of morbidity and mortality, i.e., the most powerful catastrophic responses of the biosystem. At the same time, it is impossible to reveal the potential mechanism of SA influence on the biosphere on this time scale; this requires a more detailed scale that would allow distinguishing the dynamics of the electromagnetic and corpuscular SA agents.

\subsection{Daily Scale}

From a geophysical point of view, the daily scale makes it possible to reliably distinguish the moments of onset of various SpW phenomena. From a biological point of view, this level of discretization is a good compromise between the details of the obtained biological data and the cost of collecting them when observing people.

At this scale, there are all types of studies: epidemiological, clinical and individual.

\subsubsection{Population Studies}

The class of irreversible medico-population effects which dynamics correlates with the SpW factors on a daily scale includes bursts of morbidity and mortality in large groups of people, for example, in patients of a certain hospital or several hospitals in a city or in the group of cities.

Existing studies can be classified by the type of pathology studied and the geophysical parameters (solar, heliospheric, or geomagnetic) that are used in the analysis. Taking into account the conclusion [15] that the heliobiological effect is more pronounced at high latitudes, it is also interesting to analyze the geography of its observation.

The geographical distribution is very wide and includes Spain [61], Lithuania [62-74], Russia (Moscow and St. Petersburg) [38,75-79], Cuba and Mexico [80-82], Greece [83], Bulgaria [39], Georgia [84], Azerbaijan [85], and Sweden [86]. It is interesting that southern countries make up a significant part of this list.

There are also meta-studies, such as [87], which collected data from several large population-based studies of stroke incidence in New Zealand, Australia, the United Kingdom, France, and Sweden between 1981 and 2004. The authors concluded that geomagnetic storms (Ap > $60 \mathrm{nT})$ were associated with a 19\% increase in the risk of stroke, and strong and extreme storms $(\mathrm{Ap}>100 \mathrm{nT})$ with a $52 \%$ increase.

Another large epidemiological study [88] showed a strong correlation not only of GMS, but also geomagnetic disturbances on mortality from cardiovascular diseases (CVDs) in 263 US cities.

Excluding [86], all studies found a statistical dependence between the incidences and the SpW factors dynamics. The potential SpW impact is most often manifested in the dynamics of various diseases of the cardiovascular system: overall mortality from CVD [62,76,80,83,85,88]; hospitalizations due to CVD (in general) [61,78]; ischemic heart disease $[62,75,76]$; acute myocardial infarction $[39,62,64,65,67,70,72,73,75-77,79,80,82,83,88]$; 
acute coronary syndrome $[63,68,71,74,83]$; stroke $[75,76,79,87,88]$; sharp increase in blood pressure (BP) [66,69]; and arrhythmias [84].

The list of heliogeophysical events used in the analysis includes GMS of different intensity and origin $[39,68,75,76,80-84,87,88]$; high level of GMA in combination with meteorological factors [63-66,69,70,76,78,79]; SR intensity [61]; solar flares [64,67]; moments of sharply increased SW velocity, ICME arrival to Earth [62,66-70,74,83]; SPE [62,64,65,67,68,74]; low GMA/increased GCR level [72,73,85]; reduced GCR level (FD) [38,80,82]; and Pc1 pulsations [77].

As can be seen from the above classification, there are many works on the potential influence of SpW factors on morbidity and mortality, but when they are divided according to the selected characteristics, it turns out that very few studies fall into one class. Therefore, it is very difficult to compare the results obtained by different authors: if we take into account the criteria of the biological and geophysical indicators used as well as the design of the experiment and methods of analysis, then almost every study turns out to be unique. Taken together, they show the widespread occurrence of the heliobiological effect, but do not allow us to draw conclusions about its characteristics and their variability.

Some generalizations of the results are possible only for the most popular geophysical parameter, the GMA level. The vast majority of research, including two meta-studies, report a significant increase in almost all types of morbidity studied with an increase in GMA levels. In a large series of work by Stoupel and colleagues, it is reported that days with zero GMA (and high GCR) are also associated with an increase in sudden deaths, strokes, and myocardial infarctions. These two conclusions do not contradict each other. It is possible that a shift in GMA toward a strong increase or decrease would lead to malfunctions in the body and increased incidence. This point was noted by Palmer and colleagues [15], but since then the number of works on this topic has increased significantly and the ambiguity has remained. Even with the use of very large volumes of medical statistics data, the final conclusions on the possible GMA action are multidirectional, as in the case of the meteorological effect [89].

The morbidity increase observed during CME-induced storms is much stronger than during SIR-induced storms [37-39]. It is also shown the probable heliobiological effects are manifested in different ways in the phases of the rise and fall of SA levels $[60,67,84]$.

Including in the analysis both the GMA indices and the heliospheric parameters makes it possible to identify other potentially dangerous events, in addition to the well-known GMSs; for example, SPE or sharp rises in SW density and velocity also can be accompanied by mortality increases $[62,83]$. In particular, the magnetospheric effects produced by these SpW events may be the cause of morbidity bursts sometimes observed 1-2 days before the main phase of GMS $[39,67,75,76]$. However, such studies are still insufficient to construct a clear phenomenological picture that could distinguish the possible biological effects of these two classes of events: GMS and other magnetospheric effects preceding it.

Population studies of healthy people are widely conducted in order to study the processes of adaptation to extreme conditions, such as in high latitudes or mountains, but they study the dependence of the body state on the seasons, on the light period duration and on meteorological factors.

There are very few epidemiological studies of the influence of $\mathrm{SpW}$ factors on healthy people. Most of them concern the variability of heart rate (HR) and BP levels in groups of young healthy volunteers during GMS. Analysis of HR changes on FD days have shown statistically significant but divergent results $[90,91]$.

A more complex analysis design, in which the potential biotropic GMA influence was studied depending on the current Earth's weather, showed that the biological effect is much more pronounced in certain boundaries of meteorological parameters: HR clearly increases with an increased Kp index at low temperatures and low atmospheric pressure [92].

For three independent groups of healthy year-round residents of the island of Svalbard, a study of hormone levels was carried out on geomagnetically calm and disturbed days [93]. On GMS days, all three group surveyed (miners working underground, and groups of 
men and women working on the surface) showed an increased blood concentration of the adrenal hormone cortisol, and a decrease in the level of thyroid hormones (triiodothyronine and thyroxine). The response was statistically significant and reversible, and did not lead to disease. This result is consistent with clinical observational data (see Section 3.2.4 for details) showing increased stress hormone levels during GMS.

The instability of the magnetobiological effect in the data of medical and population statistics can be seen in strong variations in its magnitude and the time lag between the onset of GMS and the response of the biological system. It can be assumed that these indicators depend on a certain set of additional external conditions, which can relate both to the criteria for selecting medical data and to additional external factors, natural or social. At present, the list of these factors cannot be established experimentally, since their number is apparently too large in comparison with the available array of studies.

The second drawback of the population approach is that, due to the strong interindividual variability of the effect, the results of such studies cannot be applied to specific patients.

\subsubsection{Individual Approach}

Individual monitoring consists of multiple repeated measurement of a certain physiological indicator in the same person for a significant period of time. It has long been known in biometeorology that people's reactions to weather changes are very individual [94]; therefore, depending on the chosen method of data analysis (average group or individual), results of different levels of detail are obtained. In mean group analysis, the effects obtained are considered to be more statistically stable. In individual analysis, the obtained patterns are not blurred by averaging over a group and are applicable for personal forecasting and possible risk assessment.

For long-term series of measurements, the most convenient indicators are measured by noninvasive methods in an outpatient setting: systolic and diastolic BP (SBP, DBP) and heart rate $(\mathrm{HR})$, with the calculation of average value and parameters of heart rate variability (HRV).

\section{Blood Pressure and Heart Rate}

Studies of patients with a diagnosis of arterial hypertension in Spain and Mexico have shown an increase in mean group blood pressure directly on GMS days $[95,96]$. The difference in BP levels between the most geomagnetically calm and disturbed days ranged from 6 to $8 \mathrm{~mm} \mathrm{Hg}$ [95].

The BP response of healthy volunteers was studied in three large groups: 86 people in Bulgaria [97], 51 people in Mexico [98], and 56 people in Japan [99]. During a period of strong GMS, in the first case, the rise in mean group BP was wide and lasted from -1 to 2 days relative to the day of the storm onset, and in the second, the greatest increase in systolic BP was observed 2 days before and 1 day after the storm.

As reported in [99], the duration of observations was only 7 days, and comparisons were made with the intensity index of the first SR mode but not with the general level of GMA. Therefore, it is not possible to compare these data with other studies, but the maximum values of SR amplitude corresponded to the minimum mean group BP.

Thus, in the mean group analysis, the possible reaction of the cardiovascular system of both patients and healthy people to severe GMS manifested as a statistically significant increase in mean BP level, mostly systolic. The conclusions on the amplitude and sign of the HR response were multidirectional.

Shepoval'nikov and Soroko [100] described the results of long-term observations of 15 polar explorers in high-latitude wintering conditions. Comparing the results obtained based on the same data in group-wide and individual analysis, the authors came to the fundamental conclusion that the operation of averaging over the group hid very important features of the effect, and sometimes the effect itself. 
Further development of the individual approach showed that in different people the phisiological state changes likely caused by GMA variations differed in sign, amplitude, and time lag between GMA rising and physiological response onset. This was true both for healthy volunteers groups and for the patients with cardiac pathologies [100-107].

The proportion of people whose individual BP dynamics correlated with GMA variations intensity ("magneto-sensitive people") also varied in different tested groups [100-107] and did not directly depend on study geographic locations. In two groups of healthy volunteers observed at different latitudes, in Sofia $\left(42^{\circ} 40^{\prime} \mathrm{N}, 23^{\circ} 20^{\prime}\right.$ E) [106] and in Syktyvkar $\left(61^{\circ} 40^{\prime} \mathrm{N}, 50^{\circ} 49^{\prime} \mathrm{E}\right)$ [104], half of the participants were magneto-sensitive, and all cases of magnetic sensitivity showed a positive correlation between the values of blood pressure and GMA. In the other studies correlations of both signs were observed, although there were significantly more positive ones.

For several patients with essential hypertension, the individual analysis of their BP indicators dynamics revealed the probable reasons for the sudden disappearance of the hypotensive effect of the prescribed therapy, namely a change in atmospheric temperature and the GMA level [101]. On the other hand, the diversity of the observed individual reactions in this group of patients made the use of the average group method of analysis ineffective.

Two papers [108,109] provide an analysis of the unique, extremely long time series of $\mathrm{BP}$ and HR registration in two healthy volunteers who wore a BP monitor continuously for 11 and 16 years, respectively. In the first case, the analysis revealed a decrease in HR during the main phase of magnetic storms [108]. In the second case, a direct relationship between $\mathrm{HR}$ and $\mathrm{WN}$ values depended on the stage of the solar cycle, while a constant inverse relationship between HR and WN variability was found [109].

\section{Heart Rate Variability}

The theoretical foundations of the HRV assessment method and the peculiarities of its application in clinical diagnostics are reviewed in [110]: the interpretation of HRV parameters, the relationship between decreased variability, the risk of disease and mortality, and the loss of regulatory capacity.

The strong sensitivity and variability of HRV parameters led to their not being used to study the possible magnetic sensitivity of sick people, and results related to heliobiology were obtained from observations of healthy people without serious cardiac pathologies.

In the initial cycle of work on the study of the possible magnetic sensitivity of HRV indicators in the 1990s, a daily resolution scale was used, where HR intervals were recorded once a day and either compared with the daily GMA level, or the samples were compared on days of magnetic storms and geomagnetically quiet days. The first studies in this design were carried out on cosmonauts during long-term flights [37,75], and important conclusions were drawn on the possible nature of the SA effect. It was shown that cosmonauts exhibited both nonspecific and specific reactions to the impact of GMS [111,112]. A nonspecific reaction occurred as a general adaptation syndrome, typical for a reaction to the effects of any external factor causing stress, such as physical and psycho-emotional overload. A specific reaction occurred as a change in vascular tone, which is typical for meteotropic reactions.

These studies show that the physiological cosmonauts reaction likely caused by GMS included the mobilization and activation of all centers of the sympathetic link, and consequently a significant increase and stabilization of the pulse and a decrease in HRV and in the strength of respiratory waves [75].

The correlations between HRV indices and GMF dynamics in young healthy volunteers [39,95-97] and older schoolchildren [103] was reported.

In works devoted to the group effect analysis [113-116], the authors reported that as the GMA level increased, the low-frequency HRV indicators, characterizing the parasympathetic activity of the autonomic nervous system, decreased, and the high-frequency 
indicators increased, indicating an increased stress level. This is consistent with findings $[111,112]$ showing that GMS is could be stressful for the body.

In works where an individual analysis method was used [102,103,116], a multidirectional reaction was observed.

Thus, the use of group analysis shows increased stress levels in healthy people during GMS. The use of individual analysis in HRV studies provides an even more diverse picture than in BP research, and significantly more observational statistics are needed to understand the reasons for such differences. It is also important to note here that the response of BP indicators in healthy people and in patients differed in the magnitude of the amplitude; in patients, the rise in blood pressure was higher. In both cases, the reaction was reversible, even if it was accompanied by a short-term deterioration in well-being.

\subsubsection{Development of Traditional Approaches}

\section{Influence of Earth Weather Factors}

Another very important aspect that remained outside the scope of consideration in most of the cited studies is the possible action of meteorological factors: atmospheric pressure, wind, humidity, and air temperature. As can be seen in Section 3.2.1 on the analysis of hospitalizations, not many studies takes into accounts not only space, but also Earth's weather in the total mass.

However, it has been shown that the same body systems can react to the action of space and Earth's weather factors [78,111,117-120]. Therefore, it was suggested that these two groups of factors may complement each other and have a cumulative effect. In this case, taking into account the possible influence of only geomagnetic factors can lead to erosion of the effect and some inconsistency in the results obtained.

The BP response, probably caused by meteorological factors, is a synchronization of slow waves in biological and physical series with a period of several days, and a possible response to GMA variations looks like a sharp one-day BP increase or decrease [101,105,118,119].

In [92], analyzing the magnetic sensitivity of BP indicators in healthy people, a new multifactorial approach to the analysis was applied. It showed that the effect of GMA is more pronounced when meteorological parameters are in certain ranges of values. In [120], the idea of the possible combined effect of meteorological and geomagnetic factors was developed based on an example of analyzing the magnetic sensitivity of vascular tone indicators in healthy volunteers. It has been shown that arterial stiffness and endothelial function, as well as BP and HR, depend simultaneously on both groups of factors. The most sensitive to the effect of space weather parameters was the pulse wave velocity, although this relationship was found only in the case of certain parameters of Earth's weather. An effect similar in meaning was also found with HR monitoring [121].

\section{Possible Influence of Geomagnetic Activity Current Level}

As a result of individual analysis of more than 300 healthy volunteers in different geographic locations, it was found that the percentage of magneto-sensitive people in different groups varied from 0 to $50 \%$ of the sample [118]. The proportion of such volunteers in each group did not correlate with the geographic latitude of the observation site (Figure 1a), but with the average GMA level during the observation period (Figure 1b).

Analysis of the variability of individual magnetosensitivity over time showed dependencies close in meaning. In [122], long-term series of individual measurements of blood microcirculation were analyzed for successive 3-month intervals. Microcirculation indices correlated with the Kp index in those seasons when the GMA level was quite high. No correlation was found in geomagnetically quiet seasons. Thus, individual magnetic sensitivity changes over time depending on the current GMA value. This effect manifests at the level of groups of volunteers as an increased proportion of magnetically dependent people, and at the level of the population as an increased number of hospitalizations. 


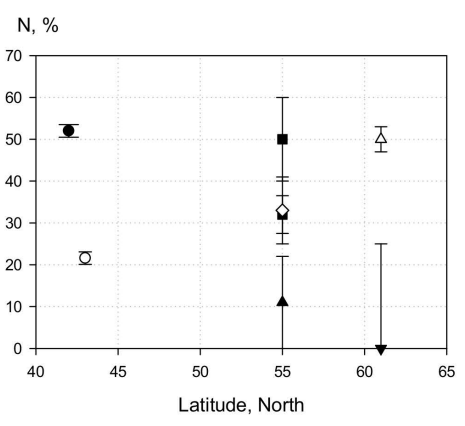

(a)

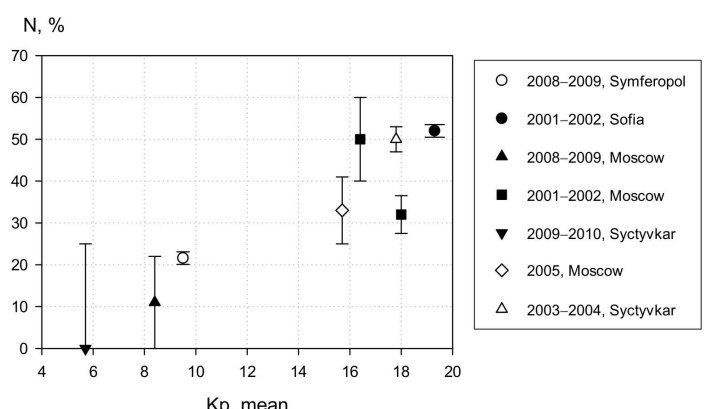

(b)

Figure 1. Dependence of magnetic sensitivity cases in groups of volunteers: (a) from latitude of observation location; (b) from average geomagnetic activity (GMA) level during monitoring period [118].

Thus, the two circumstances associated with the possible dependence of the magnetosensitive effect on the current values of meteorological factors and on the GMA level itself allowed, first, to increase the degree of detection of the effect, and, second, to reveal some regularities in its characteristics.

\subsubsection{Clinical Research}

The advantage of clinical trials over other approaches lies in the broader experimental base, i.e., the possibility to study the potential influence of SpW factors on blood parameters, hormone levels, vascular tone, electrical activity of the brain, and other physiological parameters. This method allows one to study reactions, including those of healthy people, which traditionally do not fall into the medical statistics databases.

\section{Endocrine System}

A detailed review of the biological role of melatonin is given in [123], where, from among the listed properties, it is possible to suggest pathways of the development of the response to GMS.

Studies of the effect of GMS on levels of the hormones melatonin and cortisol in patients with ischemic heart disease and hypertension were first carried out at the end of the last century [124-127]. Another group consisted of healthy volunteers and cosmonauts in flight. During GMS, suppression of melatonin secretion (more pronounced in patients than in healthy people), increased secretion of the adrenal cortex hormone cortisone (a stress hormone), and some activation of the sympathoadrenal system were observed [126-128].

The studies of Rapoport and his colleagues were mainly focused on identifying the possible response to storms in patients with coronary artery disease. However, the significance of the shift in hormone levels (mainly melatonin and cortisol) in healthy people was later confirmed $[93,129,130]$. In all cases, the reaction was reversible.

\section{Brain Research}

The method of studying the magnetosensitivity of rhythm-setting brain structures consists in electroencephalography (EEG), with subsequent calculation of indicators corresponding to certain frequency ranges, and then comparing their averaged values on geomagnetically disturbed and quiet days [131-135]. The number of parameters analyzed in such experiments turns out to be very large due to the large number of recorded assignation and spectral ranges. At the same time, changes in rhythm, which could be explained by the influence of GMS, look multidirectional and are observed in different parts of the brain. Therefore, it is not yet possible to systematize them and identify general conclusions. However, almost all authors note, first, the presence of interhemispheric asymmetry in the response of various parts of the brain to GMA, and second, the strong individuality of the 
observed reactions. Therefore, there is a danger that the averaging of results over a group of subjects partially or completely neutralizes the changes [136].

It is difficult to say to what extent the daily scale is suitable for studying the magnetic sensitivity of the brain. There is reason to believe that a high data sampling rate, perhaps minutes or hours, would be optimal for this task, which will be discussed in the next section.

\subsection{Intraday Scale}

Studies on the intraday scale of data sampling have been developed intensively in recent years due to the widespread use of new methods for long-term recording of physiological parameters and their analysis. This scale is presented in the literature only by observations of healthy people, namely by peculiarities in the dynamics of their current cardiac and brain activity and the possible contribution of geomagnetic variations to such phenomena.

Works conducted at this level of time sampling differ from those described earlier, in both the nature of the detected effect and the possible mechanisms of EMF action.

\subsubsection{EEG Registration}

A review published in 2002 [50] was devoted to substantiating the hypothesis that the main SR modes that are constantly present in the atmosphere may act as the synchronizer and be the reason for the existence of stable resonance frequencies in the human brain. If this hypothesis is correct, a dynamic connection should be observed in the rhythm of the activity of the brain and SR.

The first work to find such a connection began about 20 years ago. Pobachenko and colleagues [137] investigated the variability of the group-averaged total spectral power of the EEG and compared it with the power of SR at successive short intervals. It was found that synchronization exists between EEG and SR spectrum power and increases with overall increased GMA level. Later, these results were confirmed in [138].

Another study [139] investigated the individual sensitivity of the rhythm-setting structures of the human brain compared with the dynamics of the minute values of the horizontal GMF component. In all monitoring participants, GMF variations to a greater extent (in more than half of the registration series) were correlated with changes in the high-frequency (14-35 Hz) and low-frequency (up to $4 \mathrm{~Hz}$ ) parts of the EEG spectrum.

These results suggest that possible synchronization of brain's rhythmic activity with the GMF oscillations is not limited to SR frequencies only, but may also include lower frequencies.

\subsubsection{HR and HRV Registration}

Recording HR and its variability is much easier in terms of both recording and analysis than EEG indicators; therefore, most of the work on the study of the synchronization of geomagnetic and biological rhythms was carried out with this parameter.

In a number of works [140-143], an analysis of long multiday HR records in groups of healthy volunteers was carried out for comparison with the dynamics of the intensity of SR and variations of the total GMF vector.

In $[140,142]$, individual HR values were analyzed, without assessing the vegetative balance, and in [141,143], HRV was averaged over the group, showing the power of the spectrum of cardiointervals in different frequency ranges.

The high sampling rate of the data in these studies allowed to show that although there were no significant shifts in the mean values of cardiac parameters beyond the physiological norm, for long time spans and many periods of observation, HRV indicators turned out to be synchronized with variations in MF in the minute frequency range, as well as among a number of volunteers, although they were in different locations [142]. A pronounced synchronization of slow waves in the HRV data averaged over the group, with an average period of $67 \mathrm{~h}$ during the first half of the study period, was also observed [141]. 
This synchronization was disrupted by the onset of a strong GMS. In fact, this result is a clear illustration of the hypothesis that has long been expressed that GMSs act as the desynchronizers of geobiological rhythm.

In studies of the features of synchronization of HRV parameters, the highest correlation was found for elements of very-low-frequency oscillations (VLF) of the HRV spectrum [141]. This agrees with the conclusions [113-115] made on a daily scale of observations, only in the latter case the effect manifested as a shift in the mean when the GMA level changed, and on a minute scale as an adjustment of the current oscillation frequencies. Thus, a comparison of these results shows the natural evolution of the magnetoelectric effect with a change in scale.

Another paper [144] criticizes the correlation analysis method used in [141,143]. A discussion of the applicability of various methods of analysis in heliobiology is necessary; however, the above criticisms do not refute the described synchronization effect. First, the authors of this critical analysis themselves admit that after the refinements they made, the dependence of the VLF indicator retained a significant relationship with the GMA level, and the effect was also preserved in some volunteers. Second, the discovered effect of synchronization of HRV parameters with GMF variations was obtained by other methods without the indicated drawbacks, including nonlinear dynamics methods [142].

The differences between the works of Zenchenko et al. [145,146] and those described above were in the recording of electrocardiograms of healthy people at rest and the use of shorter observation intervals (no more than $3 \mathrm{~h}$ ) and a higher data sampling rate (minutes, not hours). Using methods of wavelet analysis, a synchronous change in the HR spectra and variations in the GMF induction vector in the frequency range of Pc5-6 pulsations (3-10 min) was shown, and the effect was observed in about $60 \%$ of cases and did not depend on the geographical point of observation.

The authors of all works noted that the magnetosensitivity varied greatly for different volunteers [140-143,145].

To elucidate the biochemical basis of the observed effect, a series of registrations of minute-by-minute values of blood biochemical parameters in healthy people was carried out [147]. The spectra of levels of cortisol and free triiodothyronine showed periods of 7-8 and 15-17 min. These periods were stable in frequency and were observed in all volunteers throughout the entire observation interval, but did not show synchronicity with minute variations of the GMF vector.

At the same time, the spectra of variations in stable nitric oxide (NO) metabolites contained periods of 7, 13, and 25-30 min, and were close to the periods of both the heart rate and the spectra of synchronous variations of the geomagnetic field vector in the frequency range $0.5-3 \mathrm{mHz}$. This result is consistent with the conclusion of Gmitrov [148], who showed that the link mediating the baroreflex response in rabbits to GMS is a change in the sensitivity of blood vessels to NO. This experiment shows that on a minute scale of sampling, fluctuations in cortisol and triiodothyronine levels are not synchronized with variations in GMF, and the observed adjustments in HR are mediated by other biochemical mechanisms, in particular NO level.

This sampling scale is the most promising in terms of studying possible ways of developing a physiological response to changes in SpW. For example, it remains to be seen whether these timing episodes are characteristic of certain allocated frequencies, such as SR or PC pulsations, or they are universal and apply to all frequency ranges.

However, for this scale, methods of analysis based on the comparison of average values are no longer suitable. Therefore, it is extremely important to discuss methods of detecting synchronization with biological series, which was touched upon in [142,144].

\section{Experimental Confirmation of the Action of Magnetic Storms}

Two key circumstances have seriously hampered the perception of heliobiological results by the biomedical and physical scientific communities: the difficulty of reproducing the biological effects of GMS in the laboratory and the theoretical substantiation of the very 
possibility of the action of an extremely weak MF, comparable in frequency and amplitude with GMF variations.

The problem with experimental reproduction of the MF effect was that in order to obtain a stable biological response, either increased (in comparison with natural) amplitudes of the MF variable component or repeated over several days periodic field exposures were required, i.e., an accumulation of effect was needed [149-152].

A detailed review of experimental work on the action of an alternating MF comparable to that of Earth is given in [153]. Here, we will only note the results that relate to the impact of the recorded GMS.

In the middle of the last century, based on an analysis of many works on magnetobiological effects, Presman [4] concluded that the higher the level of organization of a biological system, the lower the MF intensity required in an experiment to obtain a reaction. The optimal objects were living organisms, not organs, tissues, or cells.

On the other hand, it has been shown [9] that there is no strict direct correlation between the strength of GMS and the magnitude of the medical and biological consequences: often GMS with $\mathrm{Kp}=6-7$ had a more destructive effect on the state of cardiac patients in a hospital than storms with $\mathrm{Kp}=8-9$. It has been suggested, that storm intensity is only one of several characteristics that determine its potential biotropy, and its wave structure and the spectrum of the present geomagnetic pulsations can be no less important [154]. Therefore, it is possible that in order to reproduce the observed SpW effects in the laboratory, not a monochrome electromagnetic signal is needed, but a reproduction of the recorded natural GMS.

These ideas have been implemented in recent years. Krylov's group [155,156] studied the effect of GMS on the morphological and biochemical parameters of marine animals and Gurfinkel et al. [157] the reaction of vascular tone parameters in humans.

Krylov and colleagues studied the effect of a previously recorded three-component MS signal on the morphological parameters of fish and marine life. The results obtained made it possible to answer several fundamental questions of heliobiology. The first result showed the importance of the intraday location of the moment of the main phase of the storm: the biological effect was recorded only for those GMSs for which the beginning of the main phase was shifted by 6 or $12 \mathrm{~h}$ relative to the natural diurnal GMF phase. This result confirmed the hypothesis that GMS can be perceived by organisms as a violation of natural diurnal geomagnetic variability [156].

The effects of various components of the natural GMS signal have also been studied [155].

It was found that the initial broadband signal from the GMS and its low-frequency component $(\mathrm{f}<0.001 \mathrm{~Hz})$ influenced the all five tested biological systems, and their bioeffect magnitudes were the same. The impact of signal with $\mathrm{f}=0.001-5 \mathrm{~Hz}$ was a decrease in only one bioparameter. The signal, modulating Pc1 pulsations $(f=1 \mathrm{~Hz}, \mathrm{~A}=64 \mathrm{pT})$, did not have a significant effect on the parameters under study [155]. The authors concluded that the biotropic action of GMS is caused by its lowest-frequency component, which in nature is described by the Dst variation index, and not by pulsation.

In our opinion, the results presented in [155] do confirm the biotropy of the lowfrequency component of the GMS signal. However, they cannot unambiguously refute the possibility of biological action of the higher-frequency components of GMS, including Pc1 pulsations. As shown in Section 3, the biological effects of Pc-pulsations and SR known to date are manifested as frequency-amplitude synchronization of biological and geophysical rhythms. Effects of this nature could not be recorded in the experiments carried out, which, by their design, were aimed at assessing the shift in the mean.

The validity of this assumption is confirmed by the results of [158], a study on the effect of MF in the frequency range of the first SR mode $(7.8 \mathrm{~Hz}, 90 \mathrm{nT})$ on electrochemical processes in cell cultures of rat cardiomyocytes. The authors reported that the effect of SR $\mathrm{MF}$ was reversible, regardless of the field strength in the range from $20 \mathrm{pT}$ to $100 \mathrm{nT}$ and from a constant external MF. 
Changes in HRV parameters in healthy people under the influence of simulated pulsations [159] or previously recorded GMS [157] in laboratory conditions also confirm the reversible biological effect of electromagnetic oscillations in the hertz range.

Experimental laboratory studies on the effect of magnetic stimuli close in intensity to natural SR $(7-8 \mathrm{~Hz})$ on EEG parameters also remain extremely rare, but they also demonstrate the response of the biological system under study $[160,161]$.

In [160], the direct impact of the controlled variable MF $(7.8 \mathrm{~Hz}, 20 \mathrm{pT})$ on the oscillators of the human brain led to the frequency being captured by the brain and registered on the magnetoencephalogram. The effect turns out to be possible only for the selected modes present in the SR spectrum.

The parameters of the magnetic signal in the cited works were comparable with the characteristics of natural magnetic variations; therefore, it can be argued that over the past few years, the biotropicity of the GMS analog in laboratory conditions has been demonstrated quite reliably.

\section{Theoretical Studies of Possible Mechanisms of the Magneto Effect}

The second problem in heliobiology was the problem of finding a theoretical mechanism of action of extremely weak MF. The first question is: what level of organization of the biosystem has the ability to perceive the action of EMF?

Presman [4] wrote that the fundamental ideas about biological targets of EMF action can be roughly divided into two classes. Proponents of the microscopic theory consider processes occurring at the molecular level as possible primary targets of action: the effect of EMF on the orientation of diamagnetic molecules or spins, the distortion of bond angles in paramagnetic molecules, and the effect on ortho-pair transitions of water molecules. Proponents of the macroscopic theory believe that the magnetobiological effect occurs already at the level of individual organs or systems of the body, and it is useless to try to detect it at lower levels of organization. Presman himself believed that "the property of perception of weak natural EMF arises only at the level of rather complexly organized biological systems, and it is possible that this property is fully manifested only in an integral organism."

The second principal question was recently expressed in the work of Binhi and Prato $[162,163]$ : there are two types of magnetosensitivity in nature, and they most likely have different primary mechanisms. The first type is the specific magnetoreception of migrating animals, formed in the course of evolution for orientation in space. Its primary mechanism appears to be related to spin-correlated radical pairs in retinal cryptochromes or to the radical pair mechanism. This conjecture is discussed in many papers $[153,164,165]$.

The second type, which apparently is responsible for the biological effects of the temporal variability of MF, is characteristic of all organisms and manifests only sometimes under random effective combinations of electromagnetic and biochemical/physiological conditions.

Binhi and Prato [163] propose a possible physical mechanism for explaining the effects of such nonspecific magnetosensitivity, which takes into account the dynamics of nonuniformly precessing magnetic moments in biophysical targets or MF sensors that are not specialized MF receptors.

This theory, which explains the possible primary mechanism of magnetoreception at the level of biological macromolecules, is in good agreement with hypotheses that explain the next level of development of the reaction as a change in the permeability of cell membranes [166,167].

However, the problem of connecting these levels with each other and with higher ones is currently complicated by interdisciplinary barriers, since they actually belong to different scientific areas: theoretical physics, biophysics, physiology, and epidemiology. Similar difficulties and the need for them to be considered on multiple levels are noted by the authors of reviews on the biological effects of atmospheric electricity $[167,168]$, whose problems, subject matter, and research methods are very close to heliobiology. 


\section{Discussion and Conclusions}

A general overview of the presented results allows us to note several points. Studies carried out in recent years fundamentally confirm earlier conclusions obtained in the 1990s. These include:

- Increased morbidity on days of magnetic storms in patients and increased blood pressure in healthy people;

- A delay in the possible biological response (population or organism) for 0-4 days from the storm beginning;

- A specific and a nonspecific reaction to geomagnetic storms. (A nonspecific reaction occurred as a general adaptation syndrome, typical for a reaction to the effects of any external factor causing stress, such as physical and psycho-emotional overload. A specific reaction occurred as a change in vascular tone, which is typical for meteotropic reactions);

- The probable involvement of melatonin in the formation of the body's response

- Significant variability of individual responses;

- The hypothesis that the geomagnetic field of the ULF and ELF ranges $(0-300 \mathrm{~Hz})$ is an evolutionarily conditioned external synchronizer of biological rhythm, and geomagnetic storms likely cause a breakdown of this rhythm.

New evidence has appeared to support the hypothesis that geomagnetic pulsations can directly affect human biological rhythms. At the same time, it cannot be concluded from the existing results that it is precisely "special" frequencies that are close to certain biological rhythms that are biotropic.

Finally, a certain part of the new results can be considered as a significant breakthrough in heliobiological concepts, namely:

- Space and Earth weather factors potentially affect the same body systems and can modify each other's action; simultaneous consideration of these two classes of factors significantly improves the identification of the heliobiological effect and its reproducibility;

- In laboratory conditions, reliable experimental evidence of the action of various components of the storm was obtained;

- A theoretical mechanism of nonspecific magnetic sensitivity of biological systems of any level to GMF variations has been proposed;

- The biosystems response to geomagnetic variations, with no shift in the average physiological indicator value was experimental observed: the effect of synchronization of heart and brain rhythms with GMF fluctuations on the intraday time scale is shown.

At the beginning, we proposed three coordinates by which we classified the studies of potential solar-biosphere relationships existing in the literature: the time scale of data sampling, the level of organization of the biological system under study, and the degree of system response (Figure 2). The figure shows that in real studies the proposed coordinates are closely related: the larger the time scale, the higher the level of organization of the studied biosystem and the stronger the degree of its response.

Our approach allowed us to distinguish classes of phenomena of different time scales and show that it is possible to compare the effects of different classes only to a certain extent, since their manifestations differ greatly-from calm functioning within the physiological norm to catastrophe and destruction (death).

The task of systematic comparison and synthesis of the available results is greatly complicated by the variability of the approaches and formats used for describing space weather factors. A broad discussion of this problem and the development of some generally accepted methodological recommendations are necessary.

On an annual sampling scale population datasets on morbidity and mortality were exclusively studied. 


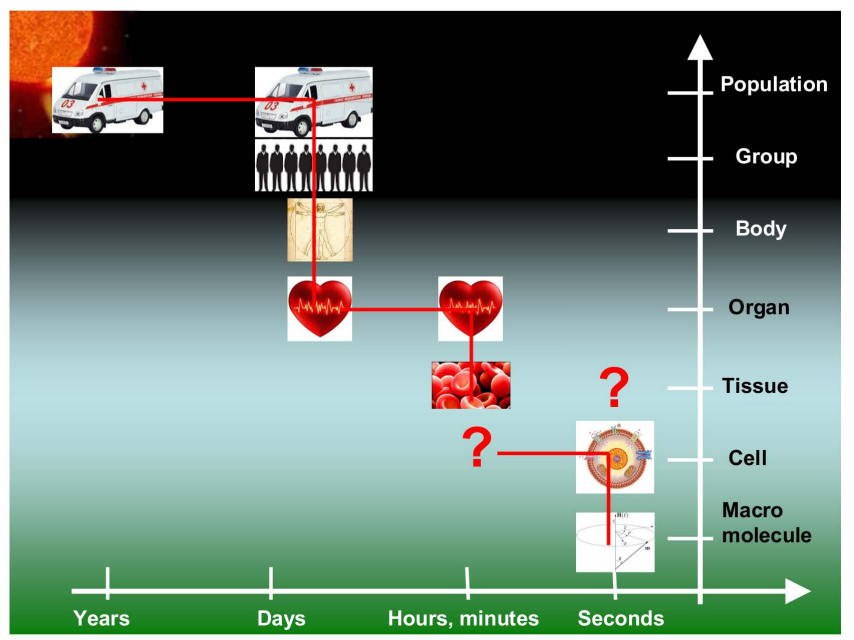

Figure 2. Layout of heliobiological results according to sampling scales of observation time and levels of organization of living systems.

For this scale, the sunspot number indices are most convenient as space weather parameters, since they reflect the most general parameter, the global variability of the main source of rhythm. The dynamics of all other SA indices are so closely correlated with these that it is impossible to distinguish between their potential contributions to biological rhythmicity. Therefore, any details on physical processes at this level are technically unattainable.

Studies on annual data series were popular in the early and mid-20th century. It is possible for them to contribute to local epidemiological studies, for example, by explaining the peculiarities of morbidity in certain areas. With the further development of databases and meta-research methods, it would be interesting to compare the possible manifestation of solar rhythmicity of some homogeneous processes at different points on Earth and in different SA cycles.

The daily scale remains very useful for studying the phenomenology of the heliobiological effect for both sick and healthy people. This level is where the widest variation in the level of organization of the studied biosystems is found, from small populations to individual body systems. There is also the widest range of the degree of tested system response, from mortality to a reversible shift in the average value of physiological parameters.

Summing up the results of heliobiological studies on a daily scale, it can be noted that they allow:

- provide data for medical and epidemiological research on the most dangerous days;

- detecting the potential response of various body systems to action of geomagnetic storms;

- $\quad$ studying the peculiarities of an individual reaction and developing algorithms for predicting individual risks.

At the same time, on a daily scale, one should also take into account the possible simultaneous influence of space and Earth weather factors. They target the same body systems, so the impact can be cumulative, and the presence of disturbances in one of them can dramatically change the response to the other.

However, it can be assumed that for a given sampling scale, brain rhythms and heart rate variability measurements are not very suitable, since their variability and sensitivity are too high.

To assess the SpW factors on this scale, it is traditional to use different geomagnetic indices; however, it is necessary to take into account what type of GMF disturbances they reflect.

Consideration of biological effects on the days of certain events in SW in the nearEarth space also makes it possible to study the possible impact of $\mathrm{SpW}$ on the bio- 
sphere through other channels not directly related to the development of GMS. Potential agents transmitting the effect of space events into the human environment can be oscillations of various ULF and ELF frequencies [29-31,40,41], the electric field of the atmosphere [42,43], weather factors [24], processes in the lithosphere [169,170]. All these factors are interconnected [171-173] and have an impact on the health and well-being of people $[42,166,167,174,175]$, but the mechanisms of such influence have not yet been studied in detail.

To solve this large class of problems, the intraday format is most convenient, which allows real-time monitoring of the possible influence of external factors on the rhythms of the brain and heart, biochemical processes of hormone synthesis, blood aggregation, electrochemical processes of the propagation of excitation through neurons and cardiomyocytes, etc.

The study of these processes dynamics is also important from a practical medical point of view, since change in brain rhythms can cause mental disorders [176-179], and heart rhythm disturbances can lead to arrhythmias, fibrillations, rises in blood pressure, and vasospasms $[60,143,180]$. All these complications likely manifest themselves on larger time scales in the form of a sharp deterioration in well-being and increased mortality.

In recent years, the need to work at several levels of detail at once and to combine the results obtained has become more and more obvious. Cifra and his colleagues wrote: "We concluded that a multiscale modeling approach integrating the molecular response to field coupled to cellular and tissue and whole organism level is crucial for a complete understanding of electromagnetic field bioeffects" [167]. A very similar idea is expressed by Hunting et al. [168].

Author Contributions: Conceptualization and writing-Zenchenko, T.A.Z. and T.K.B. All authors have read and agreed to the published version of the manuscript.

Funding: The work was carried out according to the state task of IKI RAS (the state registration number is 0120.0602992) and to the state task of ITEB RAS (the state registration number is 0120.1351298).

Institutional Review Board Statement: Not applicable.

Informed Consent Statement: Not applicable.

Data Availability Statement: Not applicable.

Acknowledgments: The authors are grateful to A.A. Petrukovich and Yu.I. Ermolaev (IKI RAS) for discussions and recommendations when writing the paper. The authors also thank the reviewers for their work in reading this lengthy review and for useful suggestions for improving individual sections.

Conflicts of Interest: The authors declare no conflict of interest.

$\begin{array}{ll}\text { Abbreviations } \\ \text { BP } & \text { blood pressure } \\ \text { CIR } & \text { Corotating Interaction Region } \\ \text { CVD } & \text { cardiovascular disease } \\ \text { DBP } & \text { diastolic blood pressure } \\ \text { ECG } & \text { electrocardiogram } \\ \text { EEG } & \text { electroencephalogram } \\ \text { FD } & \text { Forbush Decreases } \\ \text { GCR } & \text { galactic cosmic rays } \\ \text { GLE } & \text { Ground Level Enhancement - } \\ \text { GMA } & \text { geomagnetic activity } \\ \text { GMF } & \text { geomagnetic field } \\ \text { GMS } & \text { geomagnetic storm } \\ \text { ICME } & \text { interplanetary CME }\end{array}$




$\begin{array}{ll}\text { HR } & \text { heart rate } \\ \text { HRV } & \text { heart rate variability } \\ \text { MF } & \text { magnetic field } \\ \text { RF10.7 } & \text { solar radio flux at a wavelength of } 10.7 \mathrm{~cm} \\ \text { SA } & \text { solar activity } \\ \text { SBP } & \text { systolic blood pressure } \\ \text { SCR } & \text { solar cosmic rays } \\ \text { SF } & \text { solar flares } \\ \text { SR } & \text { Schumann resonance } \\ \text { SPE } & \text { solar proton events } \\ \text { SpW } & \text { space weather } \\ \text { SW } & \text { solar wind } \\ \text { VLF } & \text { very low-frequency } \\ \text { WN } & \text { Wolf numbers }\end{array}$

\section{References}

1. Chijevsky, A.L. The correlation between the variation of sun-spot activity and the rise and spreading of epidemils. Rapport le 17 Octobre 1930. In Proceedings of the XIII Congresso international de Hidrologia, Climatologia e Geologia Medicas, Programa des Sessoes Scientificas, 2 Sessao, Lisbon, Portugal, 17 October 1930.

2. Chijevsky, A.-L. Les Epidemies et Les Perturbations Electromagnetiques Du Milieu Exterieur; Depot General Le Francois: Paris, France, 1938.

3. Chizhevsky, A.-L. The Terrestrial Echo of Solar Storms; Mysl: Moscow, Russia, 1976; p. 366. (In Russian)

4. Presman, A.S. Electromagnetic Field and Wildlife; Nauka: Moscow, Russia, 1968; p. 310. (In Russian)

5. Otsuka, K.; Cornélissen, G.; Halberg, F. Chronobiology. In Chronomics and Continuous Ambulatory Blood Pressure Monitoring; Springer: Berlin/Heidelberg, Germany, 2016; Volume 31, pp. 163-184. [CrossRef]

6. Yagodinsky, V.N. The Cosmic Pulse of the Biosphere; Znanie: Moscow, Russia, 1975; p. 144. (In Russian)

7. Miroshnichenko, L.I. Solar Activity and the Earth; Nauka: Moscow, Russia, 1981; p. 145. (In Russian)

8. Vladimirsky, B.M.; Temuryants, N.A. Influence of Solar Activity on the Biosphere-Noosphere; MNEPU: Moscow, Russia, $2000 ;$ p. 374. (In Russian)

9. Breus, T.K.; Rapoport, S.I. Magnetic Storms—Biomedical and Geophysical Aspects; Sovetskiy Sport: Moscow, Russia, 2003; p. 192. (In Russian)

10. Miroshnichenko, L.I. Cosmic Rays and Evolution of the Biosphere: Search for New Approaches. In Proceedings of the International Conference "Space Weather Effects on Humans in Space and on Earth", Moscow, Russia, 4-8 June 2012; Grigoriyev, A.I., Zeleny, L.M., Eds.; Space Research Institute: Moscow, Russia, 2013; pp. 110-136.

11. Cosmophysical Correlations in Biological and Physicochemical Processes. In Proceedings of the III International Symposium, Pushchino, Russia, October 1993. (In Russian).

12. Cosmophysical Correlations in Biological and Physicochemical Processes. In Proceedings of the IV International Symposium, Pushchino, Russia, October 1996. (In Russian).

13. Cosmos and Biosphere. In Proceedings of the X International Conference, Koktebel, Ukraine, 23-28 September 2013; Available online: http:/ / biophys.ru/archive/ crimea-2013.pdf (accessed on 6 March 2021).

14. Space Weather Effects on Humans in Space and on Earth. In Proceedings of the International Conference, 4-8 June 2012; Grigoriyev, A.I.; Zeleny, L.M. (Eds.) Space Research Institute: Moscow, Russia, 2013; Available online: http://www.iki.rssi.ru/books/2013 breus1.pdf (accessed on 6 March 2021).

15. Palmer, S.J.; Rycroft, M.J.; Cermack, M. Solar and geomagnetic activity, extremely low frequency magnetic and electric fields and human health at the Earth's surface. Surv. Geophys. 2006, 27, 557-595. [CrossRef]

16. Breus, T.; Binhi, V.N.; Petrukovich, A.A. Magnetic factor in solar-terrestrial relations and its impact on the human body: Physical problems and prospects for research. Physics-Uspekhi 2016, 59, 502-510. [CrossRef]

17. Dorman, L. Solar Neutrons and Related Phenomena; Springer International Publishing: Berlin/Heidelberg, Germany, 2010; Volume 365.

18. Dorman, L.I. Cosmic Rays in the Earth's Atmosphere and Underground; Kluwer Academic Publishers: Amsterdam, The Netherlands, 2004.

19. Binhi, V.N. Magnetobiology: Underlying Physical Problems; Academic Press: San Diego, CA, USA, 2002.

20. Norval, M. Effects of solar radiation on the human immune system. J. Photochem. Photobiol. B Biol. 2001, 63, 28-40. [CrossRef]

21. Dimitrov, B.D.; Babayev, E.S. Cyclic variations in the dynamics of flu incidence in Azerbaijan, 1976-2000. Epidemiol. Infect. 2014, 143, 13-22. [CrossRef]

22. Davis, G.E.; Lowell, W.E. Solar cycles and their relationship to human disease and adaptability. Med. Hypotheses 2006, 67, 447-461. [CrossRef] 
23. Villoresi, G.; Breus, T.K.; Iucci, N.; Dorman, L.I.; Rapoport, S.I. The influence of geophysical and social effects on the incidences of clinically important pathologies (Moscow, 1979-1981). Phys. Medica. 1994, 10, 79-91.

24. Gray, L.J.; Beer, J.; Geller, M.; Haigh, J.D.; Lockwood, M.; Matthes, K.; Cubasch, U.; Fleitmann, D.; Harrison, G.; Hood, L.; et al. Solar influences on climate. Rev. Geophys. 2010, 48. [CrossRef]

25. Kleczek, J. Solar Flare Index.; Publ. Inst. Centr. Astron.: Prague, Czech Republic, 1952.

26. Ataç, T.; Özgüç, A. Flare Index of Solar Cycle 22. Sol. Phys. 1998, 180, 397-407. [CrossRef]

27. Ataç, T.; Özgüç, A. Flare Index during the Rising Phase of Solar Cycle 23. Sol. Phys. 2001, 198, 399-407. [CrossRef]

28. Yermolaev, Y.I.; Yermolaev, M.Y. Solar and interplanetary sources of geomagnetic storms: Space weather aspects. Izv. Atmos. Ocean. Phys. 2010, 46, 799-819. [CrossRef]

29. De, S.; De, B.; Bandyopadhyay, B.; Paul, S.; Haldar, D.; Barui, S. Studies on the shift in the frequency of the first Schumann resonance mode during a solar proton event. J. Atmos. Sol. Terr. Phys. 2010, 72, 829-836. [CrossRef]

30. Singh, B.; Tyagi, R.; Hobara, Y.; Hayakawa, M. X-rays and solar proton event induced changes in the first mode Schumann resonance frequency observed at a low latitude station Agra, India. J. Atmos. Sol. Terr. Phys. 2014, 113, 1-9. [CrossRef]

31. Sátori, G.; Williams, E.; Price, C.; Boldi, R.; Koloskov, A.; Yampolski, Y.; Guha, A.; Barta, V. Effects of Energetic Solar Emissions on the Earth-Ionosphere Cavity of Schumann Resonances. Surv. Geophys. 2016, 37, 757-789. [CrossRef]

32. Miroshnichenko, L.I. Retrospective analysis of GLEs and estimates of radiation risks. J. Space Weather. Space Clim. 2018,8, A52. [CrossRef]

33. Tsurutani, B.T.; Gonzalez, W.D.; Gonzalez, A.L.C.; Guarnieri, F.L.; Gopalswamy, N.; Grande, M.; Kamide, Y.; Kasahara, Y.; Lu, G.; Mann, I.; et al. Corotating solar wind streams and recurrent geomagnetic activity: A review. J. Geophys. Res. Space Phys. 2006, 111. [CrossRef]

34. Borovsky, J.E.; Denton, M.H. Differences between CME-driven storms and CIR-driven storms. J. Geophys. Res. Space Phys. 2006, 111. [CrossRef]

35. Yermolaev, Y.I.; Lodkina, I.G.; Nikolaeva, N.S.; Yermolaev, M.Y. Dynamics of Large-Scale Solar-Wind Streams Obtained by the Double Superposed Epoch Analysis: 2. Comparisons of CIRs vs. Sheaths and MCs vs. Ejecta. Sol. Phys. 2017, 292, 193. [CrossRef]

36. Richardson, I.G. Solar wind stream interaction regions throughout the heliosphere. Living Rev. Sol. Phys. 2018, 15, 1-95. [CrossRef] [PubMed]

37. Breus, T.K.; Baevskii, R.M.; Nikulina, G.A.; Chibisov, S.M.; Chernikova, A.G.; Pukhlianko, M.; Oraevskii, V.N.; Halberg, F.; Cornelissen, G.; Petrov, V.M. Effect of geomagnetic activity on the human body in extreme conditions and correlation with data from laboratory observations. Biofizika 1998, 43, 811-818. [PubMed]

38. Villoresi, G.; Ptitsyna, N.G.; Tiasto, M.I.; Iucci, N. Myocardial infarct and geomagnetic disturbances: Analysis of data on morbidity and mortality. Biofizika 1998, 43, 623-631.

39. Dimitrova, S.; Stoilova, I.; Georgieva, K.; Taseva, T.; Jordanova, M.; Maslarov, D. Solar and geomagnetic activity and acute myocardial infarction morbidity and mortality. Fundam. Space Res. Supl. Compt. Rend. Acad. Bulg. Sci. 2009, 3, 161-165.

40. Kornilov, I.A.; Kornilov, O.I. Specific Behavior of VLF Emissions and the First Schumann Resonance Related to SC. Geomagn. Aeron. 2005, 45, 627-632.

41. Matveyeva, E.; Shchepetnov, R. Temporal characteristics and medical aspects of Pc1 geomagnetic pulsations. J. Atmos. Sol. Terr. Phys. 2007, 69, 1747-1752. [CrossRef]

42. Rycroft, M.; Israelsson, S.; Price, C. The global atmospheric electric circuit, solar activity and climate change. J. Atmos. Sol. Terr. Phys. 2000, 62, 1563-1576. [CrossRef]

43. Rycroft, M.J.; Nicoll, K.A.; Aplin, K.L.; Harrison, R.G. Recent advances in global electric circuit coupling between the space environment and the troposphere. J. Atmos. Sol. Terr. Phys. 2012, 90-91, 198-211. [CrossRef]

44. Loewe, C.A.; Prölss, G.W. Classification and mean behavior of magnetic storms. J. Geophys. Res. Space Phys. 1997, 102, 14209-14213. [CrossRef]

45. Bianchi, C.; Meloni, A. Natural and man-made terrestrial electromagnetic noise: An outlook. Ann. Geophys. 2007, 50, 435-446.

46. Pilipenko, V.A.; Kleimenova, N.G.; Kozyreva, O.V.; Yumoto, K.; Bitterly, J. Longitudinal features of PC5 pulsations in the morning and evening sectors. Geomagn. Aeron. 1997, 37, 64-74.

47. Kozyreva, O.V.; Kleimenova, N.G.; Schott, J.-J. Geomagnetic pulsations at the initial phase of a magnetic storm. Geomagn. Aeron. 2004, 44, 33-41.

48. Kozyreva, O.V.; Kleimenova, N.G. Variations in the ULF index of geomagnetic pulsations during strong magnetic storms. Geomagn. Aeron. 2009, 49, 425-437. [CrossRef]

49. Kvandal, P.; Landsverk, S.A.; Bernjak, A.; Stefanovska, A.; Kvernmo, H.D.; Kirkebøen, K.A. Low-frequency oscillations of the laser Doppler perfusion signal in human skin. Microvasc. Res. 2006, 72, 120-127. [CrossRef] [PubMed]

50. Cherry, N. Schumann Resonances, a plausible biophysical mechanism for the human health effects of Solar. Nat. Hazards 2002, 26, 279-331. [CrossRef]

51. Price, C. ELF Electromagnetic Waves from Lightning: The Schumann Resonances. Atmosphere 2016, 7, 116. [CrossRef]

52. Nickolaenko, A.P.; Koloskov, A.V.; Hayakawa, M.; Yampolski, Y.M.; Budanov, O.V.; Korepanov, V.E. 11-year solar cycle in Schumann resonance data as observed in Antarctica. Sun Geosph. 2015, 10, 39-49.

53. Shvets, A.V.; Nickolaenko, A.P.; Chebrov, V.N. Effect of Solar Flares on the Schumann-Resonance Frequences. Radiophys. Quantum Electron. 2017, 60, 186-199. [CrossRef] 
54. Hayes, D.P. Influenza pandemics, solar activity cycles, and vitamin D. Med. Hypotheses 2010, 74, 831-834. [CrossRef]

55. Gumarova, L.; Cornélissen, G.; Hillman, D.; Halberg, F. Geographically selective assortment of cycles in pandemics: Meta-analysis of data collected by Chizhevsky. Epidemiol. Infect. 2012, 141, 2173-2184. [CrossRef]

56. Qu, J. Is sunspot activity a factor in influenza pandemics? Rev. Med. Virol. 2016, 26, 309-313. [CrossRef]

57. Wickramasinghe, N.C. Is the 2019 novel coronavirus related to a spike of cosmic rays? Adv. Genet. 2020, 106, 119-122. [CrossRef]

58. Vieira, C.L.Z.; Janot-Pacheco, E.; Lage, C.; Pacini, A.; Koutrakis, P.; Cury, P.R.; Shaodan, H.; Pereira, L.A.; Saldiva, P.H.N. Long-term association between the intensity of cosmic rays and mortality rates in the city of Sao Paulo. Environ. Res. Lett. 2018, 13, 24009. [CrossRef]

59. Halberg, F.; Cornelissen, G.; Otsuka, K.; Watanabe, Y.; Katinas, G.S.; Burioka, N.; Delyukov, A.; Gorgo, Y.; Zhao, Z.; Weydahl, A.; et al. Cross-spectrally coherent $\sim 10,5$ - and 21-year biological and physical cycles, magnetic storms and myocardial infarctions. Neuroendocrinol. Lett. 2000, 21, 233-258.

60. Cornelissen, G.; Halberg, F.; Breus, T.K.; Syutkina, E.V.; Baevskii, R.M.; Weydahl, A.; Watanabe, Y.; Otsuka, K.; Siegelova, J.; Fiser, B.; et al. Non-photic solar associations of heart rate variability and myocardial infarction. J. Atmos. Sol. Terr. Phys. 2002, 64, 707-728. [CrossRef]

61. Fdez-Arroyabe, P.; Fornieles-Callejón, J.; Santurtún, A.; Szangolies, L.; Donner, R.V. Schumann resonance and cardiovascular hospital admission in the area of Granada, Spain: An event coincidence analysis approach. Sci. Total. Environ. 2020, 705, 135813. [CrossRef]

62. Vaičiulis, V.; Radišauskas, R.; Ustinavičienè, R.; Kalinienè, G.; Tamošiūnas, A. Associations of morbidity and mortality from coronary heart disease with heliogeophysical factors. Environ. Sci. Pollut. Res. 2016, 23, 18630-18638. [CrossRef]

63. Vencloviene, J.; Grazuleviciene, R.; Babarskiene, R.; Dėdele,, A.; Grazulevicius, T. Short-term nitrogen dioxide exposure and geomagnetic activity interaction: Contribution to emergency hospitalization for acute coronary syndrome. Int. J. Environ. Health Res. 2011, 21, 149-160. [CrossRef]

64. Vencloviene, J.; Babarskiene, R.; Slapikas, R.; Sakalyte, G. The association between phenomena on the Sun, geomagnetic activity, meteorological variables, and cardiovascular characteristic of patients with myocardial infraction. Int. J. Biometeorol. 2013, 57, 797-804. [CrossRef]

65. Vencloviene, J.; Babarskiene, R.; Slapikas, R. The association between solar particle events, geomagnetic storms, and hospital admissions for myocardial infarction. Nat. Hazards 2012, 65, 1-12. [CrossRef]

66. Vencloviene, J.; Babarskiene, R.M.; Dobozinskas, P.; Sakalyte, G.; Lopatienè, K.; Mikelionis, N. Effects of Weather and Heliophysical Conditions on Emergency Ambulance Calls for Elevated Arterial Blood Pressure. Int. J. Environ. Res. Public Health 2015, 12, 2622-2638. [CrossRef]

67. Vencloviene, J.; Antanaitiene, J.; Babarskiene, R. The association between space weather conditions and emergency hospital admissions for myocardial infarction during different stages of solar activity. J. Atmos. Sol. Terr. Phys. 2016, 149, 52-58. [CrossRef]

68. Vencloviene, J.; Babarskiene, R.M.; Kiznys, D. A possible association between space weather conditions and the risk of acute coronary syndrome in patients with diabetes and the metabolic syndrome. Int. J. Biometeorol. 2016, 61, 159-167. [CrossRef]

69. Vencloviene, J.; Braziene, A.; Dobozinskas, P. Short-Term Changes in Weather and Space Weather Conditions and Emergency Ambulance Calls for Elevated Arterial Blood Pressure. Atmosphere 2018, 9, 114. [CrossRef]

70. Vencloviene, J.; Radisauskas, R.; Vaiciulis, V.; Kiznys, D.; Bernotiene, G.; Kranciukaite-Butylkiniene, D.; Tamosiunas, A. Associations between Quasi-biennial Oscillation phase, solar wind, geomagnetic activity, and the incidence of acute myocardial infarction. Int. J. Biometeorol. 2020, 64, 1207-1220. [CrossRef] [PubMed]

71. Ziubryte, G.; Siauciunaite, V.; Jarusevicius, G.; McCraty, R. Local earth magnetic field and ischemic heart disease: Peculiarities of interconnection. Cardiovasc. Disord. Med. 2018, 3, 1-3. [CrossRef]

72. Stoupel, E.; Tamoshiunas, A.; Radishauskas, R.; Bernotiene, G.; Abramson, E.; Israelevich, P. Acute myocardial infarction (AMI)(n-11026) on days of zero geomagnetic activity (GMA) and the following week: Differences at months of maximal and minimal solar activity (SA) in solar cycles 23 and 24. J. Basic Clin. Physiol. Pharmacol. 2012, 23, 5-9. [CrossRef] [PubMed]

73. Stoupel, E.; Richardas, R.; Vidmantas, V.; Gailute, B.; Abdonas, T.; Evgeny, A. Data about Natural History of Some Acute Coronary Events at Days of High Cosmic Ray (CRA)-Neutron Activity and Following 48 Hours (2000-2012). Health 2016, 8, 402-408. [CrossRef]

74. Kiznys, D.; Vencloviene, J.; Milvidaite, I. The associations of geomagnetic storms, fast solar wind, and stream interaction regions with cardiovascular characteristic in patients with acute coronary syndrome. Life Sci. Space Res. 2020, 25, 1-8. [CrossRef]

75. Oraevski1, V.N.; Kuleshova, V.P.; Gurfinkel', I.F.; Guseva, A.V.; Rapoport, S.I. [Medico-biological effect of natural electromagnetic variations]. Biofizika 1999, 43, 844-848.

76. Gurfinkel', I.; Kuleshova, V.P.; Oraevskiǔ, V.N. Assessment of the effect of a geomagnetic storm on the frequency of appearance of acute cardiovascular pathology. Biofizika 1998, 43, 654-658. (In Russian)

77. Kleimenova, N.; Kozyreva, O.; Breus, T.; Rapoport, S. Pc1 geomagnetic pulsations as a potential hazard of the myocardial infarction. J. Atmos. Sol. Terr. Phys. 2007, 69, 1759-1764. [CrossRef]

78. Ozheredov, V.A.; Breus, T.K.; Gurfinkel, Y.I.; Revich, B.A.; Mitrofanova, T.A. Influence of some weather factors and geomagnetic activity on the development of severe cardiological pathologies. Biophysics 2010, 55, 110-119. [CrossRef]

79. Shaposhnikov, D.; Revich, B.; Gurfinkel, Y.; Naumova, E. The influence of meteorological and geomagnetic factors on acute myocardial infarction and brain stroke in Moscow, Russia. Int. J. Biometeorol. 2013, 58, 799-808. [CrossRef] [PubMed] 
80. Mendoza, B.; De La Peña, S.S. Solar activity and human health at middle and low geomagnetic latitudes in Central America. Adv. Space Res. 2010, 46, 449-459. [CrossRef]

81. Rodriquez-Taboada, E.R.; Sierra-Figueredo, P.; Figueredo, S.S. Geomagnetic activity related to acute myocardial infarctions: Relationship in a reduced population and time interval. Geofis. Int. 2004, 43, 265-269.

82. Mendoza, B.; Diaz-Sandoval, R. Effects of solar activity on myocardial infarction deaths in low geomagnetic latitud regions. Nat. Hazards 2004, 32, 25-36. [CrossRef]

83. Katsavrias, C.; Preka-Papadema, P.; Moussas, X.; Apostolou, T.; Theodoropoulou, A.; Papadima, T. Helio-geomagnetic influence in cardiological cases. Adv. Space Res. 2013, 51, 96-106. [CrossRef]

84. Giannaropoulou, E.; Papailiou, M.; Mavromichalaki, H.; Gigolashvili, M.; Tvildiani, L.; Janashia, K.; Preka-Papadema, P.; Papadima, T. A study on the various types of arrhythmias in relation to the polarity reversal of the solar magnetic field. Nat. Hazards 2014, 70, 1575-1587. [CrossRef]

85. Stoupel, E.; Babayev, E.S.; Abramson, E.; Sulkes, J. Days of "Zero" level geomagnetic activity accompanied by the high neutron activity and dynamics of some medical events-Antipodes to geomagnetic storms. Health 2013, 5, 855-861. [CrossRef]

86. Messner, T.; Häggström, I.; Sandahl, I.; Lundberg, V. No covariation between the geomagnetic activity and the incidence of acute myocardial infarction in the polar area of northern Sweden. Int. J. Biometeorol. 2002, 46, 90-94. [CrossRef]

87. Feigin, V.L.; Parmar, P.G.; Barker-Collo, S.; Bennett, D.A.; Anderson, C.S.; Thrift, A.G.; Stegmayr, B.; Rothwell, P.M.; Giroud, M.; Bejot, Y.; et al. Geomagnetic Storms Can Trigger Stroke. Stroke 2014, 45, 1639-1645. [CrossRef]

88. Vieira, C.L.Z.; Alvares, D.; Blomberg, A.; Schwartz, J.; Coull, B.; Huang, S.; Koutrakis, P. Geomagnetic disturbances driven by solar activity enhance total and cardiovascular mortality risk in 263 U.S. cities. Environ. Health 2019, 18, 1-10. [CrossRef]

89. Zenchenko, T.A.; Breus, T.K. Influence of climate and weather on health and well-being of people. Modern concepts. Geosph. Res. 2020, 3, 80-96. [CrossRef] [PubMed]

90. Mavromichalaki, H.; Papailiou, M.; Dimitrova, S.; Babayev, E.S.; Loucas, P. Space weather hazards and their impact on human cardio-health state parameters on Earth. Nat. Hazards 2012, 64, 1447-1459. [CrossRef]

91. Papailiou, M.; Kudela, K.; Stetiarova, J.; Giannaropoulou, E.; Mavromichalaki, H.; Dimitrova, S. The effect of cosmic ray intensity variations and geomagnetic disturbances on the physiological state of aviators. Astrophys. Space Sci. Trans. 2011, 7, 373-377. [CrossRef]

92. Ozheredov, V.A.; Chibisov, S.M.; Blagonravov, M.L.; Khodorovich, N.A.; Demurov, E.A.; Goryachev, V.A.; Kharlitskaya, E.V.; Eremina, I.S.; Meladze, Z.A. Influence of geomagnetic activity and earth weather changes on heart rate and blood pressure in young and healthy population. Int. J. Biometeorol. 2016, 61, 921-929. [CrossRef]

93. Breus, T.; Boiko, E.; Zenchenko, T. Magnetic storms and variations in hormone levels among residents of North Polar areaSvalbard. Life Sci. Space Res. 2015, 4, 17-21. [CrossRef]

94. Assman, D. Human Sensitivity to Weather; Hydrometeoizdat: Saint Petersburg, Russia, 1966; p. 247. (In Russian)

95. Ghione, S.; Mezzasalma, L.; Del Seppia, C.; Papi, F. Do geomagnetic disturbances of solar origin affect arterial blood pressure? J. Hum. Hypertens. 1998, 12, 749-754. [CrossRef]

96. Azcárate, T.; Mendoza, B. Influence of geomagnetic activity and atmospheric pressure in hypertensive adults. Int. J. Biometeorol. 2017, 339, 1364-1592. [CrossRef]

97. Dimitrova, S.; Stoilova, I.; Cholakov, I. Influence of local geomagnetic storms on arterial blood pressure. Bioelectromagnetics 2004, 25, 408-414. [CrossRef]

98. Azcárate, T.; Mendoza, B.; De La Peña, S.S.; Martínez, J. Temporal variation of the arterial pressure in healthy young people and its relation to geomagnetic activity in Mexico. Adv. Space Res. 2012, 50, 1310-1315. [CrossRef]

99. Mitsutake, G.; Otsuka, K.; Hayakawa, M.; Sekiguchi, M.; Cornelissen, G.; Halberg, F. Does Schumann resonance affect our blood pressure? Biomed. Pharmacother. 2005, 59, S10-S14. [CrossRef]

100. Shepoval'nikov, V.N.; Soroko, S.I. Meteochuvstvitel'nost' cheloveka/otv. red. V. A.Yakovlev; AN Respubliki Kyrgyzstan. In Fiziologii i Eksperimental'noi Patologii Vysokogor'ya; Ilim: Bishkek, Kyrgyzstan, 1992; p. 247. (In Russian)

101. Zenchenko, T.A.; Tsagareishvili, E.V.; Oshchepkova, E.V.; Rogoza, A.N.; Breus, T.K. To the questions of the influence of geomagnetic and meteorological activity on patients with arterial hypertension. Clin. Med. 2007, 85, 31-35. (In Russian)

102. Chernouss, S.; Vinogradov, A.; Vlassova, E. Geophysical Hazard for Human Health in the Circumpolar Auroral Belt: Evidence of a Relationship between Heart Rate Variation and Electromagnetic Disturbances. Nat. Hazards 2001, 23, 121-135. [CrossRef]

103. Belisheva, N.K.; Konradov, A.A. The value of variations in the geomagnetic field for the functional state of the human body in high latitudes. Geophys. Process. Biosph. 2005, 4, 44-52.

104. Zenchenko, T.A.; Varlamova, N.G. Hemodynamic response characteristics of healthy people to changes in meteorological and geomagnetic factors in the north. Izv. Atmos. Ocean. Phys. 2015, 51, 858-870. [CrossRef]

105. Zenchenko, T.A.; Tsandekov, P.A.; Grigoriev, P.E.; Merzlyi, A.M.; Zenchenko, K.I.; Khorseva, N.I.; Grigal, P.P. Pattern of relations between physiological and psychophysiological parameters of human organism and geomagnetic and meteorological factors. Geophys. Process. Biosph. 2008, 7, 25-36. (In Russian)

106. Zenchenko, T.A.; Dimitrova, S.; Stoilova, I.; Breus, T.K. Individual types of blood pressure reactions of practically healthy people to the effect of geomagnetic activity. Clin. Med. 2009, 4, 18-23. (In Russian)

107. Poskotinova, L.V.; Grigoriev, P.E. The Dependence of Typological Autonomic Features Reactions of Healthy Persons on Background Helio-Meteofactors. Hum. Ecol. 2008, 5, 3-8. (In Russian) 
108. Wanliss, J.; Cornélissen, G.; Halberg, F.; Brown, D.; Washington, B. Superposed epoch analysis of physiological fluctuations: Possible space weather connections. Int. J. Biometeorol. 2017, 62, 449-457. [CrossRef]

109. Watanabe, Y.; Cornélissen, G.; Halberg, F.; Otsuka, K.; Ohkawa, S.-I. Associations by signatures and coherences between the human circulation and helio- and geomagnetic activity. Biomed. Pharmacother. 2000, 55, s76-s83. [CrossRef]

110. Shaffer, F.; McCraty, R.; Zerr, C.L. A healthy heart is not a metronome: An integrative review of the heart's anatomy and heart rate variability. Front. Psychol. 2014, 5, 1040. [CrossRef]

111. Breus, T.K.; Baevskii, R.M.; Chernikova, A.G. Effects of geomagnetic disturbances on humans functional state in space flight. J. Biomed. Sci. Eng. 2012, 5, 341-355. [CrossRef]

112. Baevsky, R.M.; Petrov, V.M.; Cornelissen, G.; Halberg, F.; Orth-Gomer, K.; Akerstedt, T.; Otsuka, K.; Breus, T.; Siegelova, J.; Dusek, J.; et al. Meta-analyzed heart rate variability, exposure to geomagnetic storms, and the risk of ischemic heart disease. Scr. Med. 1997, 70, 11543511.

113. Otsuka, K.; Cornélissen, G.; Weydahl, A.; Holmeslet, B.; Hansen, T.; Shinagawa, M.; Kubo, Y.; Nishimura, Y.; Omori, K.; Yano, S.; et al. Geomagnetic disturbance associated with decrease in heart rate variability in a subarctic area. Biomed. Pharmacother. 2000, 55, s51-s56. [CrossRef]

114. Oinuma, S.; Kubo, Y.; Otsuka, K.; Yamanaka, T.; Murakami, S.; Matsuoka, O.; Ohkawa, S.; Cornélissen, G.; Weydahl, A.; Holmeslet, B.; et al. Graded response of heart rate variability, associated with an alteration of geomagnetic activity in a subarctic area. Biomed. Pharmacother. 2002, 56, 284-288. [CrossRef]

115. Otsuka, K.; Cornelissen, G.; Halberg, F. Heart Rate Variability Reflecting the Dynamics of Solar Activity. In Chronomics and Continuous Ambulatory Blood Pressure Monitoring; Springer: Berlin/Heidelberg, Germany, 2016; Available online: https://link. springer.com/chapter/10.1007/978-4-431-54631-3_14\#citeas (accessed on 6 March 2021).

116. Dimitrova, S.; Angelov, I.; Petrova, E. Solar and geomagnetic activity effects on heart rate variability. Nat. Hazards 2013, 69, 25-37. [CrossRef]

117. Gurfinkel, Y.; Breus, T.; Zenchenko, T.; Ozheredov, V. Investigation of the Effect of Ambient Temperature and Geomagnetic Activity on the Vascular Parameters of Healthy Volunteers. Open J. Biophys. 2012, 2, 46-55. Available online: https://www.researchgate.net/publication/267845138_Investigation_of_the_Effect_of_Ambient_Temperature_and_ Geomagnetic_Activity_on_the_Vascular_Parameters_of_Healthy_Volunteers (accessed on 6 March 2021). [CrossRef]

118. Zenchenko, T.A. Method of successive approximations in the task of studying the mechanism of individual heliometeotropic reactions. In Proceedings of the International Conference "The influence of Space Weather on Human Health in Space and on Earth", Moscow, Russia, 4-7 June 2012; pp. 633-648. Available online: http:/ /www.iki.rssi.ru/books/2013breus2.pdf (accessed on 6 March 2021). (In Russian).

119. Breus, T.K.; Gurfinkel, Y.I.; Zenchenko, T.A.; Ozheredov, V.A. Comparative analysis of different vascular tone sensitivity parameters to meteorological and geomagnetic factors. Izv. Atmos. Ocean. Phys. 2010, 46, 965-972. [CrossRef]

120. Gurfinkel, Y.I.; Ozheredov, V.A.; Breus, T.K.; Sasonko, M.L. The effects of space and terrestrial weather factors on arterial stiffness and endothelial function in humans. Biophysics 2018, 63, 299-306. [CrossRef]

121. Sasonko, M.L.; Ozheredov, V.A.; Breus, T.K.; Ishkov, V.N.; Klochikhina, O.A.; Gurfinkel, Y.I. Combined influence of the local atmosphere conditions and space weather on three parameters of 24-h electrocardiogram monitoring. Int. J. Biometeorol. 2018, 63, 93-105. [CrossRef]

122. Zenchenko, T.A.; Poskotinova, L.V.; Rekhtina, A.G.; Zaslavskaya, R.M. Relation between Microcirculation Parameters and Pc3 Geomagnetic Pulsations. Biophysics 2010, 55, 646-651. [CrossRef]

123. Dominguez-Rodriguez, A.; Abreu-Gonzalez, P.; Sanchez-Sanchez, J.J.; Kaski, J.C.; Reiter, R.J. Melatonin and circadian biology in human cardiovascular disease. J. Pineal Res. 2010, 49, 14-22. [CrossRef]

124. Rapoport, S.I.; Breus, T.K. Melatonin as a most important factor in the action of weak natural magnetic fields on patients with hypertensive disease and coronary heart disease. Part 1. Klin. Med. 2011, 89, 9-14.

125. Rapoport, S.I.; Breus, T.K. Melatonin as a most important factor in the action of weak natural magnetic fields on patients with hypertensive disease and coronary heart disease. Part 2. Klin. Med. 2011, 89, 4-7.

126. Rapoport, S.I.; Malinovskaia, N.K.; Oraevskií, V.N.; Komarov, F.I.; Nosovskií, A.M.; Vetterberg, L. Effects of disturbances of natural magnetic field of the Earth on melatonin production in patients with coronary heart disease. Klin Med. 1997, 75, 24-26. Available online: https:/ / pubmed.ncbi.nlm.nih.gov/9273394/ (accessed on 6 March 2021).

127. Rapoport, S.I.; Boldypakova, T.D.; Malinovskaia, N.K.; Oraevskiü, V.N.; Meshcheriakova, S.A.; Breus, T.K.; Sosnovskiü, A.M. Magnetic storms as a stress factor. Biofizika 1998, 43, 632-639.

128. Rapoport, S.I.; Shatalova, A.M.; Oraevskiı̌, V.N.; Malinovskaia, N.K.; Vetterberg, L. Produktsiia melatonina u bol'nykh gipertonicheskoĭ bolezn'iu vo vremia magnitnykh bur' [Melatonin production in hypertonic patients during magnetic storms]. Ter Arkh. 2001, 73, 29-33. (In Russian)

129. Burch, J.B.; Reif, J.S.; Yost, M.G. Geomagnetic activity and human melatonin metabolite excretion. Neurosci. Lett. 2008, 438, 76-79. [CrossRef]

130. Weydahl, A.; Sothern, R.B.; Cornelissen, G.; Wetterberg, L. Geomagnetic activity influences the melatonin secretion at latitude 70 degrees N. Biomed. Pharmacother. 2001, 55, 57s-62s. [CrossRef]

131. Agadzhanyan, N.A.; Makarova, I.I.; Golovko, M.Y.; Dyachkova, L.Y.; Kanonidi, H.D. Electrophysiological and neuro-chemical analysis of biological effects of disturbances in the earth's magnetic field. Aerosp. Environ. Med. 2002, 36, 26-32. (In Russian) 
132. Kanunikov, I.E.; Kiselev, B.V. Influence of the geomagnetic field on the recurrent characteristics of the electroencephalogram. Hum. Ecol. 2014, 12, 47-54. (In Russian)

133. Rozhkov, V.P.; Trifonov, M.I.; Bekshaev, S.S.; Belisheva, N.K.; Pryanichnikov, S.V.; Soroko, S.I. Evaluation of the influence of geomagnetic and solar activity on the bioelectric processes of the human brain with the help of a structural function. Sechenov Russ. J. Physiol. 2016, 102, 1479-1494. (In Russian)

134. Pavlov, K.I.; Syrtsev, A.V.; Mukhin, V.N.; Archimuk, A.N.; Mikheeva, E.A.; Nikolaeva, S.V.; Andieva, N.M.; Kamenskaya, V.G.; Petrenko, M.I. The Effect of Environmental Factors on the Cognitive Functions of Cadets at a Military Institute. Izv. Atmos. Ocean. Phys. 2019, 55, 1465-1487. [CrossRef]

135. Allakhverdiev, A.R.; Babayev, E.S. Functional State of the Brain of Elderly Women at Rest and in Mental Stress under Varying Geomagnetic Conditions. Hum. Physiol. 2020, 46, 408-416. [CrossRef]

136. Carrubba, S.; Frilot, C.; Chesson, A.; Marino, A. Evidence of a nonlinear human magnetic sense. Neuroscience 2007, 144, 356-367. [CrossRef]

137. Pobachenko, S.V.; Kolesnik, A.G.; Borodin, A.S.; Kalyuzhin, V.V. The contingency of parameters of human encephalograms and Schumann resonance electromagnetic fields revealed in monitoring studies. Biophysics 2006, 51, 480-483. [CrossRef]

138. Saroka, K.S.; Vares, D.E.; Persinger, M.A. Similar Spectral Power Densities Within the Schumann Resonance and a Large Population of Quantitative Electroencephalographic Profiles: Supportive Evidence for Koenig and Pobachenko. PLoS ONE 2016, 11, e0146595. [CrossRef]

139. Poskotinova, L.V.; Zenchenko, T.A.; Krivonogova, E.V.; Demin, D.B. Methodological aspects of monitoring individual reactions of the bioelectrical activity of the brain under conditions of variations in the geomagnetic field in the Arctic. Bull. Ural Med. Acad. Sci. 2018, 15, 316-323. [CrossRef]

140. Alabdulgade, A.; Maccraty, R.; Atkinson, M.; Vainoras, A.; Berškienė, K.; Mauricienè, V.; Navickas, Z.; Šmidtaitè, R.; Landauskas, M.; Daunoravičienė, A. Human heart rhythm sensitivity to earth local magnetic field fluctuations. J. Vibroeng. 2015, 17, 3271-3278.

141. McCraty, R.; Atkinson, M.; Stolc, V.; Alabdulgader, A.A.; Vainoras, A.; Ragulskis, M. Synchronization of Human Autonomic Nervous System Rhythms with Geomagnetic Activity in Human Subjects. Int. J. Environ. Res. Public Health 2017, 14, 770. [CrossRef] [PubMed]

142. Timofejeva, I.; McCraty, R.; Atkinson, M.; Joffe, R.; Vainoras, A.; Alabdulgader, A.; Ragulskis, M. Identification of a Group's Physiological Synchronization with Earth's Magnetic Field. Int. J. Environ. Res. Public Health. 2017, 14, 998. [CrossRef]

143. Alabdulgader, A.; McCraty, R.; Atkinson, M.; Dobyns, Y.; Vainoras, A.; Ragulskis, M.; Stolc, V. Long-Term Study of Heart Rate Variability Responses to Changes in the Solar and Geomagnetic Environment. Sci. Rep. 2018, 8, 1-14. [CrossRef]

144. Mattoni, M.; Ahn, S.; Fröhlich, C.; Fröhlich, F. Exploring the relationship between geomagnetic activity and human heart rate variability. Graefe's Arch. Clin. Exp. Ophthalmol. 2020, 120, 1371-1381. [CrossRef]

145. Zenchenko, T.A.; Jordanova, M.; Poskotinova, L.V.; Medvedeva, A.A.; Alenikova, A.E.; Khorseva, N.I. Synchronization between human heart rate dynamics and Pc5 geomagnetic pulsations at different latitudes. Biophysics 2014, 59, 965-972. [CrossRef]

146. Zenchenko, T.A.; Medvedeva, A.A.; Khorseva, N.I.; Breus, T.K. Synchronization of human heart-rate indicators and geomagnetic field variations in the frequency range of 0.5-3.0 mHz. Izv. Atmos. Ocean. Phys. 2014, 50, 736-744. [CrossRef]

147. Zenchenko, T.A.; Medvedeva, A.A.; Potolitsyna, N.N.; Parshukova, O.I.; Boiko, E.R. Correlation of the dynamics of minute-scale heart rate oscillations and biochemical parameters of the blood in healthy subjects to Pc5-6 geomagnetic pulsations. Biophysics 2015, 60, 309-316. [CrossRef]

148. Gmitrov, J. Baroreceptor stimulation enhanced nitric oxide vasodilator responsiveness, a new aspect of baroreflex physiology. Microvasc. Res. 2015, 98, 139-144. [CrossRef]

149. Lednev, V.V.; Belova, N.A.; Rozhdestvenskaya, Z.E.; Tiras, K.P. Biological effects of weak alternating magnetic fields and biological precursors of earthquakes. Geophys. Processes Biosph. 2003, 2, 7-18.

150. Lednev, V.V.; Belova, N.A.; Ermakov, A.M.; Akimov, E.B.; Tonevitsky, A.G. Modulation of cardiac rhythm in the humans exposed to extremely weak alternating magnetic fields. Biophysics 2008, 53, 648-654. [CrossRef]

151. Martynyuk, V.S.; Temur'Yants, N.A.; Temuryants, N. Extremely low magnetic fields as a factor of modulation and synchronization of infradian biorhythms in animals. Izv. Atmospheric Ocean. Phys. 2010, 46, 820-829. [CrossRef]

152. Belova, N.A.; Ermakov, A.M.; Znobishcheva, A.V.; Skrebnitskaia, L.K.; Lednev, V.V. [Effect of the extremely weak alternating magnetic fields on the regeneration of planarians and the gravitropic response of plants]. Biofizika 2010, 55, 704-709.

153. Krylov, V.V. Biological effects related to geomagnetic activity and possible mechanisms. Bioelectromagnetics 2017, 38, 497-510. [CrossRef] [PubMed]

154. Kleimenova, N.G.; Troitskaya, V.A. Geomagnetic pulsations as one of the environmental factors of the environment. Biophysics 1992, 37, 429-438.

155. Biasutti, M.A. Comparative Analysis of Forms and Wikis as Tools for Online Collaborative Learning. Comput. Educ. 2017, 107, 158-171. [CrossRef]

156. Krylov, V.V.; Kantserova, N.P.; Lysenko, L.A.; Osipova, E.A. A simulated geomagnetic storm unsynchronizes with diurnal geomagnetic variation affecting calpain activity in roach and great pond snail. Int. J. Biometeorol. 2019, 63, 241-246. [CrossRef]

157. Gurfinkel, Y.I.; Vasin, A.L.; Pishchalnikov, R.Y.; Sarimov, R.M.; Sasonko, M.L.; Matveeva, T.A. Geomagnetic storm under laboratory conditions: Randomized experiment. Int. J. Biometeorol. 2017, 62, 501-512. [CrossRef] 
158. Elhalel, G.; Price, C.; Fixler, D.; Shainberg, A. Cardioprotection from stress conditions by weak magnetic fields in the Schumann Resonance band. Sci. Rep. 2019, 9, 1-10. [CrossRef]

159. Caswell, J.M.; Singh, M.; Persinger, M.A. Simulated sudden increase in geomagnetic activity and its effect on heart rate variability: Experimental verification of correlation studies. Life Sci. Space Res. 2016, 10, 47-52. [CrossRef]

160. Volkov, A.I.; Savintseva, A.A.; Shabanov, G.A.; Lebedev, Y.A.; Rybchenko, A.A.; Maximov, A.L. About resonance interaction of schumann's biospherical frequencies and human brain rhythms Weak and superweak fields and radiation in biology and medicine: Abstracts. In Proceedings of the VI International Congress, St. Petersburg, Russia, 2-6 July 2012; Available online: www.biophys.ru/archive/congress2012/proc-p168.htm (accessed on 6 March 2021).

161. Mulligan, B.P.; Persinger, M.A. Experimental simulation of the effects of sudden increases in geomagnetic activity upon quantitative measures of human brain activity: Validation of correlational studies. Neurosci. Lett. 2012, 516, 54-56. [CrossRef]

162. Binhi, V.N.; Prato, F.S. A physical mechanism of magnetoreception: Extension and analysis. Bioelectromagnetics 2017, 38, 41-52. [CrossRef]

163. Binhi, V.N.; Prato, F.S. Rotations of macromolecules affect nonspecific biological responses to magnetic fields. Sci. Rep. 2018, 8 , 1-11. [CrossRef]

164. Zaporozhan, V.; Ponomarenko, A. Mechanisms of Geomagnetic Field Influence on Gene Expression Using Influenza as a Model System: Basics of Physical Epidemiology. Int. J. Environ. Res. Public Health 2010, 7, 938-965. [CrossRef]

165. Close, J. Are stress responses to geomagnetic storms mediated by the cryptochrome compass system? Proc. R. Soc. B Boil. Sci. 2012, 279, 2081-2090. [CrossRef]

166. Panagopoulos, D.J.; Balmori, A. On the biophysical mechanism of sensing atmospheric discharges by living organisms. Sci. Total Environ. 2017, 599-600, 2026-2034. [CrossRef]

167. Cifra, M.; Apollonio, F.; Liberti, M.; García-Sánchez, T.; Mir, L.M. Possible molecular and cellular mechanisms at the basis of atmospheric electromagnetic field bioeffects. Int. J. Biometeorol. 2021, 65, 59-67. [CrossRef]

168. Hunting, E.R.; Matthews, J.; Hernáez, P.F.D.A.; England, S.J.; Kourtidis, K.; Koh, K.; Nicoll, K.; Harrison, R.G.; Manser, K.; Price, C.; et al. Challenges in coupling atmospheric electricity with biological systems. Int. J. Biometeorol. 2021, 65, 45-58. [CrossRef]

169. Anagnostopoulos, G.; Spyroglou, I.; Rigas, A.; Preka-Papadema, P.; Mavromichalaki, H.; Kiosses, I. The sun as a significant agent provoking earthquakes. Eur. Phys. J. Spéc. Top. 2021, 230, 287-333. [CrossRef]

170. Hayakawa, M.; Hattori, K.; Ando, Y. Natural Electromagnetic Phenomena and Electromagnetic Theory: A Review. IEEJ Trans. Fundam. Mater. 2004, 124, 72-79. [CrossRef]

171. Li, M.; Lu, J.; Zhang, X.; Shen, X. Indications of Ground-based Electromagnetic Observations to A Possible LithosphereAtmosphere-Ionosphere Electromagnetic Coupling before the 12 May 2008 Wenchuan MS 8.0 Earthquake. Atmosphere 2019, 10, 355. [CrossRef]

172. Walker, S.N.; Kadirkamanathan, V.; Pokhotelov, O.A. Changes in the ultra-low frequency wave field during the precursor phase to the Sichuan earthquake: DEMETER observations. Ann. Geophys. 2013, 31, 1597-1603. [CrossRef]

173. Athanasiou, M.A.; Machairidis, G.G.; David, C.N.; Anagnostopoulos, G.C. Enhanced ULF electromagnetic Activity Detected by DEMETER above Seismogenic Regions. arXiv 2013, arXiv:1302.6680. Available online: https://arxiv.org/ftp/arxiv/papers/1302 /1302.6680.pdf (accessed on 6 March 2021).

174. Price, C.; Williams, E.; Elhalel, G.; Sentman, D. Natural ELF fields in the atmosphere and in living organisms. Int. J. Biometeorol. 2021, 65, 85-92. [CrossRef] [PubMed]

175. Guo, Y.; Liu, Y.; Wang, X. Electromagnetic activity: A possible player in epilepsy. Acta Epileptol. 2020, 2, 1-6. [CrossRef]

176. Anagnostopoulos, G.; Basta, M.; Stefanakis, Z.; Vassiliadis, V.; Vgontzas, A.; Rigas, A.; Koutsomitros, S.; Baloyannis, S.; Papadopoulos, G. A study of correlation between seismicity and mental health: Crete, 2008-2010. Geomatics Nat. Hazards Risk 2013, 6, 45-75. [CrossRef]

177. Anagnostopoulos, G.; Basta, M.; Vgontzas, A.; Rigas, A.; Vassiliadis, V.; Baloyannis, S.; Koutsomitros, T. Differential effects of earthquakes on patients with bipolar disorder versus schizophrenia: Findings from Crete, Greece, 2008-2010. Psychiatriki 2019, 30, 193-203. [CrossRef] [PubMed]

178. Klimesch, W. EEG alpha and theta oscillations reflect cognitive and memory performance: A review and analysis. Brain Res. Rev. 1999, 29, 169-195. [CrossRef]

179. Arakaki, X.; Lee, R.; King, K.S.; Fonteh, A.N.; Harrington, M.G. Alpha desynchronization during simple working memory unmasks pathological aging in cognitively healthy individuals. PLoS ONE 2019, 14, e0208517. [CrossRef]

180. Sajadieh, A.; Nielsen, O.W.; Rasmussen, V.; Hein, H.O.; Abedini, S.; Hansen, J.F. Increased heart rate and reduced heart-rate variability are associated with subclinical inflammation in middle-aged and elderly subjects with no apparent heart disease. Eur. Hear. J. 2004, 25, 363-370. [CrossRef] 